\title{
Nuclear Fallout
}

Decision Aid

for First Responders

E. J. Archibald

B. R. Buddemeier

\section{August 2010}

घive ensution

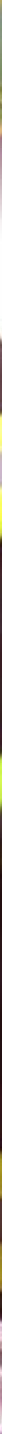




\section{Acknowledgements}

This research was performed under an appointment to the Department of Homeland Security (DHS) Scholarship and Fellowship Program, administered by the Oak Ridge Institute for Science and Education (ORISE) through an interagency agreement between the U.S. Department of Energy (DOE) and DHS. ORISE is managed by Oak Ridge Associated Universities (ORAU) under DOE contract number DE-AC05-06OR23100. All opinions expressed in this paper are the author's and do not necessarily reflect the policies and views of DHS, DOE, or ORAU/ORISE. Lawrence Livermore National Laboratory (LLNL) would like to acknowledge the support and leadership of DHS Science and Technology and the CBRNE Branch of the Federal Emergency Management Agency's Response Operations. Special thanks to Erika Olsen and Emily Archibald for their critical review of this report.

\section{Disclaimer}

This document was prepared as an account of work sponsored by an agency of the United States government. Neither the United States government nor Lawrence Livermore National Security, LLC, nor any of their employees makes any warranty, expressed or implied, or assumes any legal liability or responsibility for the accuracy, completeness, or usefulness of any information, apparatus, product, or process disclosed, or represents that its use would not infringe privately owned rights. Reference herein to any specific commercial product, process, or service by trade name, trademark, manufacturer, or otherwise does not necessarily constitute or imply its endorsement, recommendation, or favoring by the United States government or Lawrence Livermore National Security, LLC. The views and opinions of authors expressed herein do not necessarily state or reflect those of the United States government or Lawrence Livermore National Security, LLC, and shall not be used for advertising or product endorsement purposes.

\section{Auspices Statement}

This work performed under the auspices of the U.S. Department of Energy by Lawrence Livermore National Laboratory under Contract DE-AC52-07NA27344. 


\title{
Nuclear Fallout Decision Aid for First Responders
}

\author{
E. J. Archibald \\ B. R. Buddemeier
}

\begin{abstract}
If terrorists detonated an improvised nuclear device (IND) in an urban area, thousands of people would die from the blast, and many more would become sick or die from exposure to fallout radiation. Proper sheltering and evacuation can protect people from fallout and save lives. This project provides guidance to first responders as to when to evacuate and what route to take to protect themselves against fallout radiation. The radiation exposure from sheltering and evacuation was examined to determine when to evacuate. Data was collected by calculating evacuation radiation exposure for about 800 scenarios. Each scenario consisted of testing three straight-line evacuation routes (i.e., they do not avoid obstacles) for a given starting point in a
\end{abstract}

model-produced fallout pattern. It was found that evacuation dose increases with increasing outdoor dose rate at starting point. A means of estimating maximum likely evacuation dose given starting-point dose rate was developed. This estimation was utilized to develop charts that guide evacuation time based on indoor radiation rate and building protection factor. These charts enable first responders to decide when to evacuate using only their measured indoor radiation rate and building protection factor. For $98 \%$ of the 800 automatically generated evacuations, evacuation at the time recommended by the chart had about the same or lower dose than evacuating after 12 hours. For 45 scenarios in which paths were more realistic and did avoid obstacles, evacuation at the time recommended resulted in exposures about the same or lower than evacuation after 12 hours. The charts only work when the better lateral path is taken. The better lateral path can be discovered $94 \%$ of the time in a simple fallout pattern by following a lateral path with decreasing radiation rates. For fallout patterns with greater spread, this is true only $79 \%$ of the time. Determination of observationbased evacuation times and routes will give first responders the ability to make good evacuation decisions even in the absence of advanced scientific information or modeling provided they have access to a high range radiation dose rate instrument. It is recommended that a broader analysis look into other factors not accounted for in this study before widespread application of these results. 


\section{Contents}

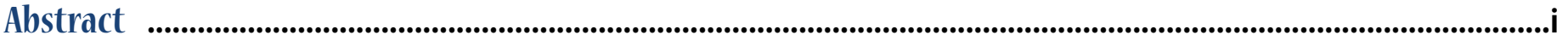

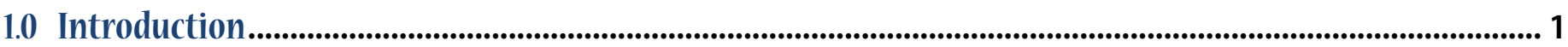

1.1 The Threat ............................................................................................................................................................................................

1.2 Improvised Nuclear Device (IND) Fallout Hazard...........................................................................................................................1

1.3 Need for Guidance.................................................................................................................................................................................2

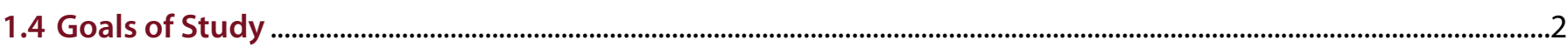

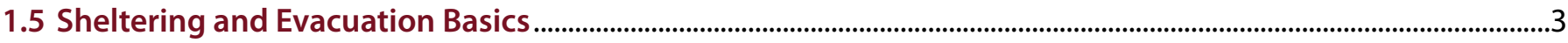

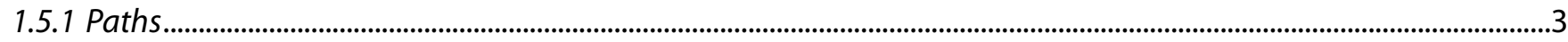

2.0 Technical Approach ........................................................................................................................................ 4

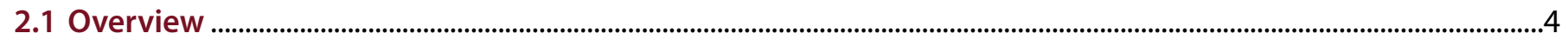

2.2 Dataset Used........................................................................................................................................................................................4

2.3 Calculation of Sheltered Dose ........................................................................................................................................................

2.4 Calculation of Evacuation Doses ......................................................................................................................................................

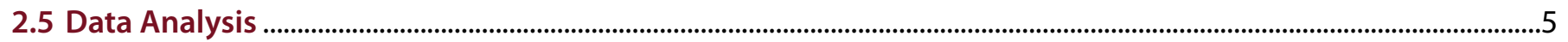

2.5.1 July 14th Data ........................................................................................................................................................................

2.5.2 December 14th Data .............................................................................................................................................................

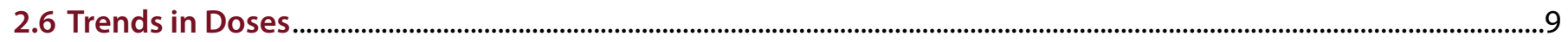

2.7 Estimation of Evacuation Dose Using Outdoor Rate...............................................................................................................9

2.8 Calculation of Recommended Evacuation Times.................................................................................................................9

2.9 Limitations, Assumptions, and Sources of Error...................................................................................................................10

2.91 Weather and Scenario Bias .................................................................................................................................................... 10

2.9.2 Sources of Error........................................................................................................................................................................... 10

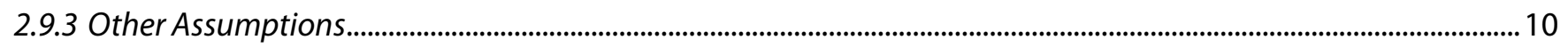

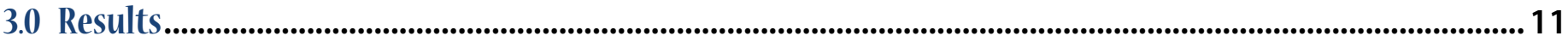

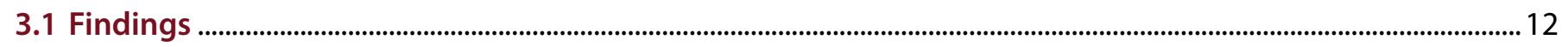

3.2 Guidance for Responders .............................................................................................................................................................12

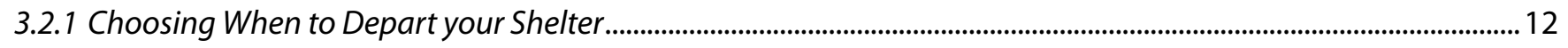

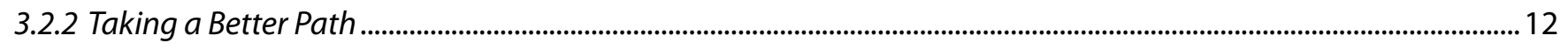

3.2.3 Monitoring the Path .......................................................................................................................................................................... 13

4.0 Examples......................................................................................................................................................... 14

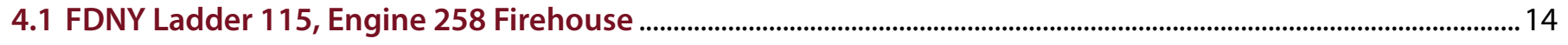

4.2 FDNY Battalion 8, Engine 2, Ladder 2 Firehouse.....................................................................................................................16

4.3 FDNY Engine 34, Ladder 21 Firehouse ………………………………………………………………………………....2

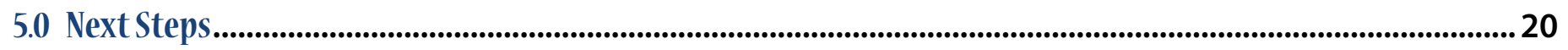

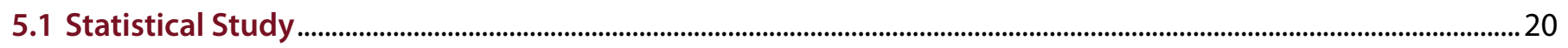

5.2 Broader Analysis and Risk Analysis .............................................................................................................................2

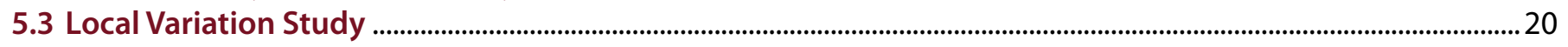

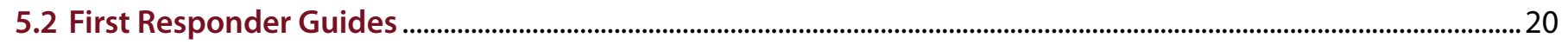

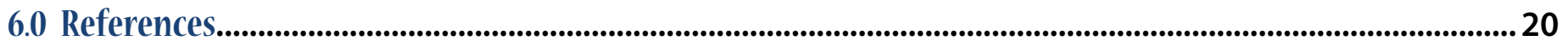


Appendix A:SEVURAS Guide......................................................................................................................................2 21

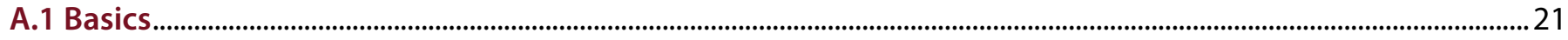

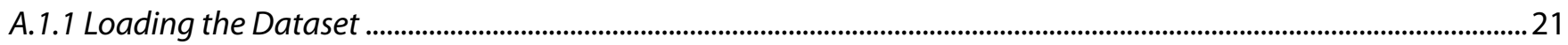

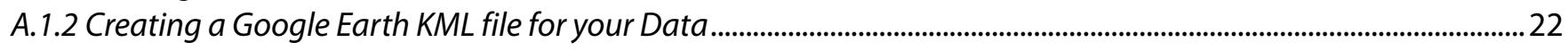

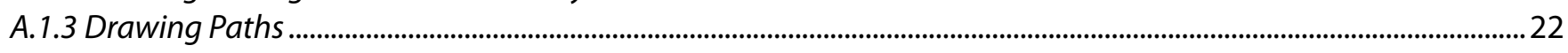

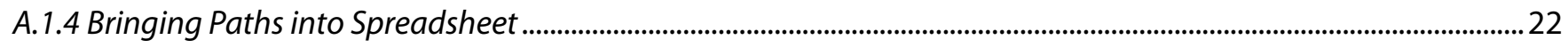

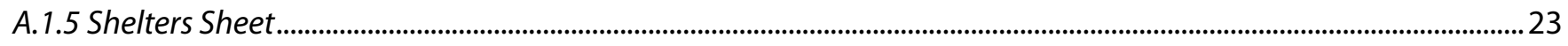

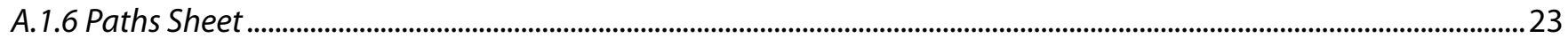

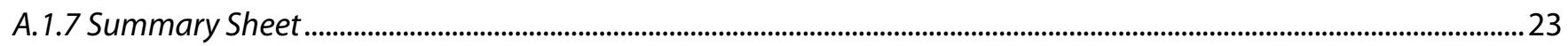

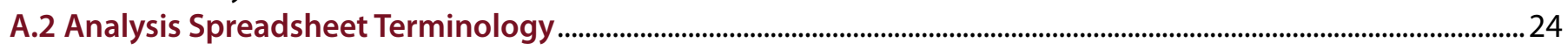

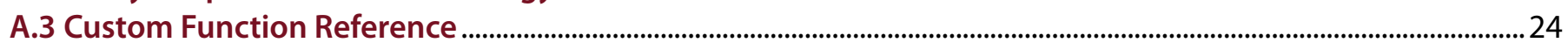




\subsection{Introduction}

\subsection{The Threat}

The threat of a nuclear attack on a major city is a growing national security concern. Of this threat President Obama remarked, "One nuclear weapon exploded in one city-be it New York or Moscow, Islamabad or Mumbai, Tokyo or Tel Aviv, Paris or Prague-could kill hundreds of thousands of people. And no matter where it happens, there is no end to what the consequences might be for our global safety, our security, our society, our economy, to our ultimate survival." Within the federal government this is a concern at all levels. In "A World at Risk," Congress conducted detailed research into this threat. Over the past few years, nuclear terrorism has been researched and investigated in national laboratories and considered by dozens of federal agencies responsible for every aspect of federal response. Local governments from New York to Los Angeles, especially of large urban centers, have likewise showed an interest.

\subsection{Improvised Nuclear Device (IND) Fallout Hazard}

The primary delayed effect from a ground-level nuclear detonation is called "fallout." Fallout is generated when the dust and debris excavated by the explosion is combined with radioactive fission products produced in the nuclear explosion and drawn upward by the heat of the event. This forms a cloud that rapidly climbs through the atmosphere, potentially up to 5 miles high for a 10-kiloton (10-kt) explosion, from which highly radioactive particles coalesce and drop back down to earth as the cloud cools. For a ground-level low-yield nuclear detonation (10 kt), the fallout created could settle on the ground and create dangerous levels of radiation for
10 to 20 miles downwind. ${ }^{1}$ Proper protection from radioactive fallout could save many lives.

It is important to be inside shelter when the fallout arrives, as this is the time when the radiation levels are highest. Fallout arrival times vary with yield and weather, but if you are outside of the buildingcollapse area immediately surrounding the detonation, then you should have several minutes before fallout arrives. If you are outdoors or in a car, seek the nearest adequate shelter. Adequate shelters are locations that have as much earth, building materials, or distance between the occupants and exposed horizontal surfaces as possible and will reduce exposure to the occupant by a factor of 10 or more. Examples of adequate shelter include the following:
- Basements, usually against a basement wall.

- Multistory brick or concrete structures.

- Office buildings (central core or underground sections).

- Multistory shopping malls (away from roof or exterior walls).

- Tunnels, subways, and other underground areas.

Spending the first hour in an adequate shelter can keep exposures non-lethal. ${ }^{2}$ The federal planning guidance ${ }^{1}$ for response to a nuclear detonation recommends that "people should expect to remain sheltered for at least 12 to 24 hours." Depending on the level of protection offered by the shelter and the ability to determine the best evacuation route, optimal shelter departure time may be only a few hours in some cases.

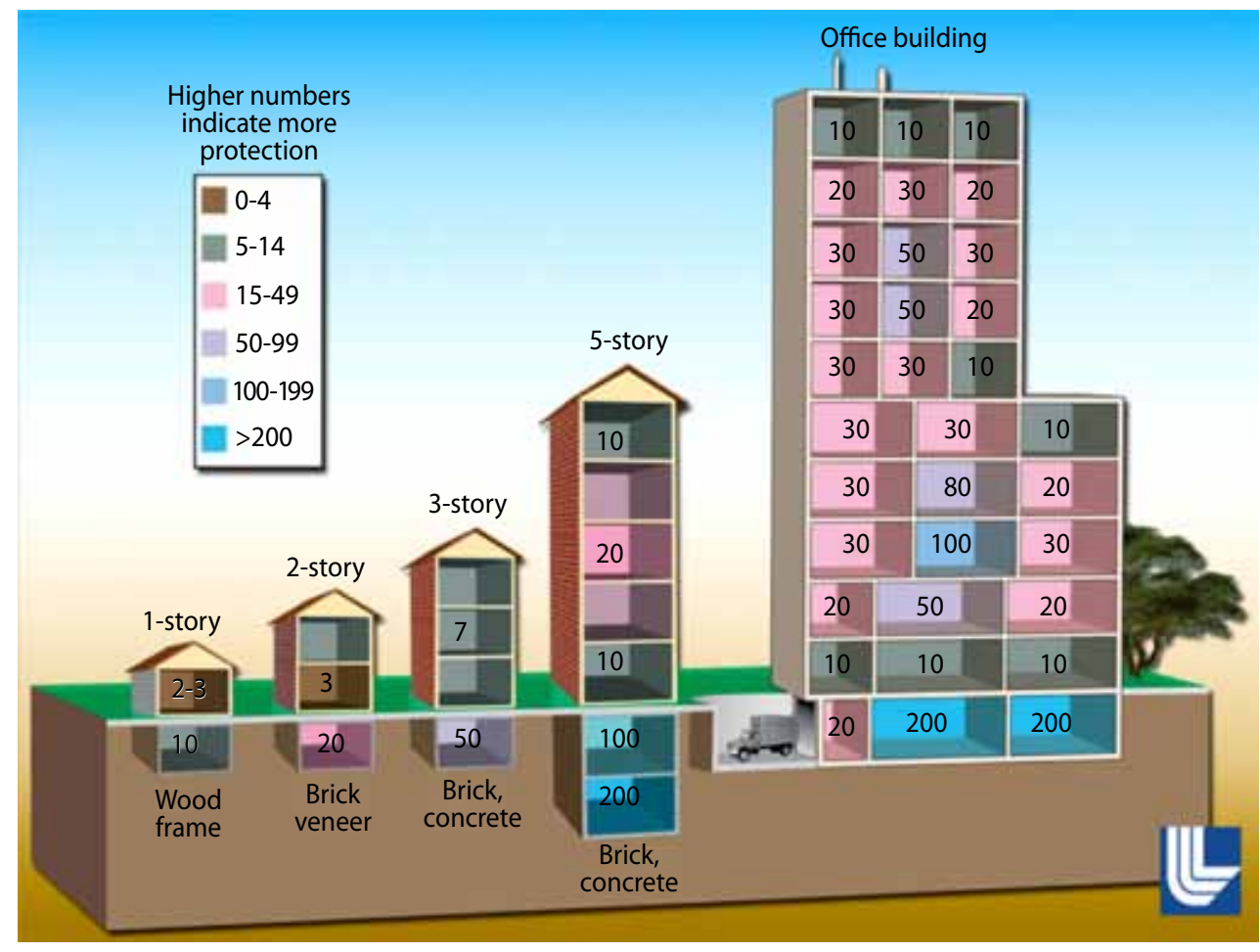

Figure 1: Protection factors (PFs) vary for different buildings and different locations within a building. 
The determination of an appropriate time and route to evacuate can be very difficult without knowing the fallout movement. A lack of fast situational awareness and good communication will likely leave many to make choices on their own. This could cause people to make poor choices in regard to evacuation routes and shelter departure timing.

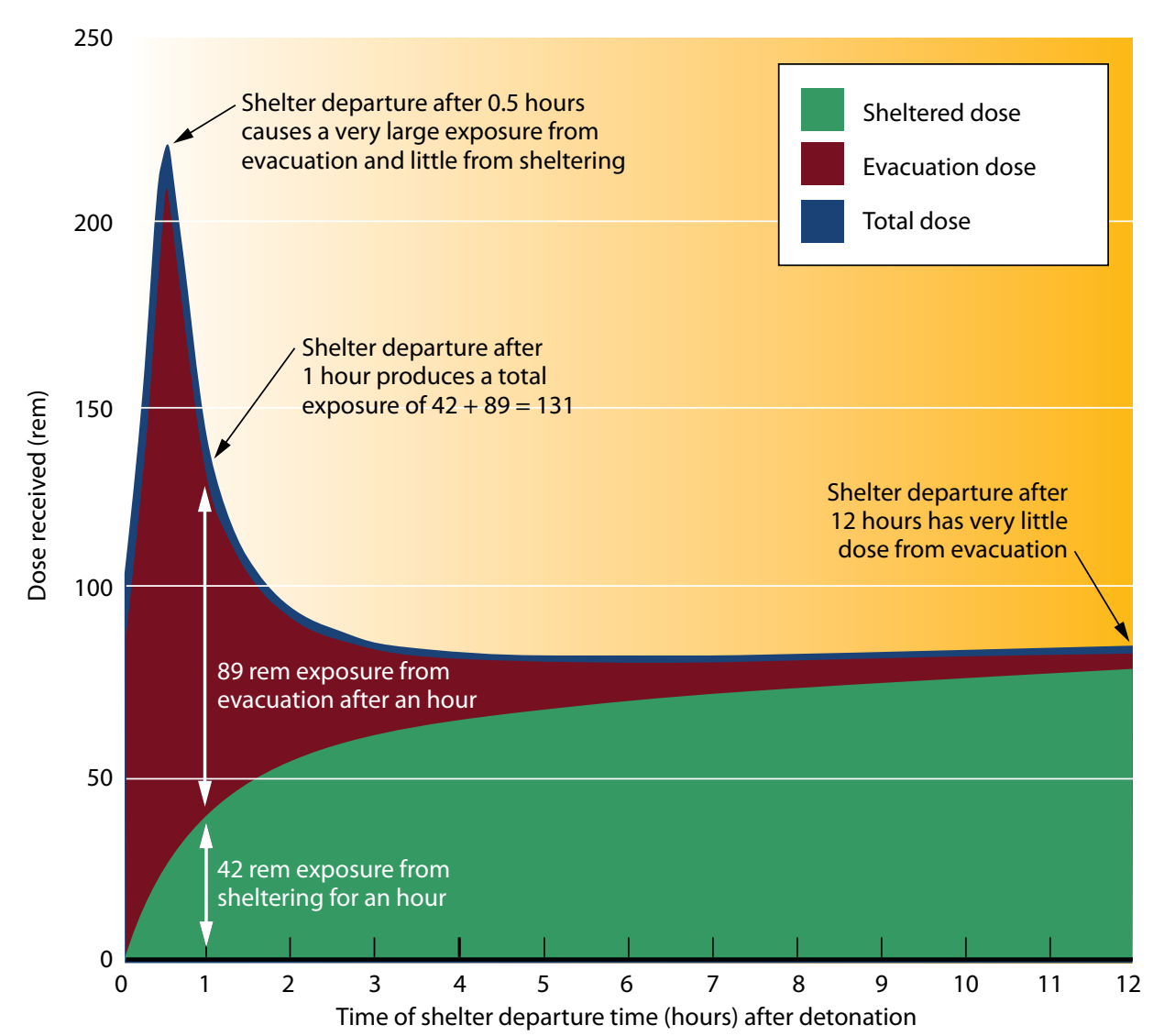

Figure 2. Total dose received depends on time of shelter departure.

\subsection{Need for Guidance}

In such a large disaster, even first responders will lack the detailed technical information needed to make informed evacuation decisions. Although many first responders have the equipment necessary to monitor radiation levels, guidance to inform their evacuation decisions does not exist. The purpose of 
person in the same area. To obtain the sheltered exposure, divide the outdoor exposure by the PF. Figure 1 shows approximate PFs for various structures.

Dose: The amount of radiation exposure received.

Dose Rate: The rate at which radiation exposure is occurring.

Rem: A unit of absorbed dose that accounts for biological effects of radiation. For the purposes of this study, 1 rem $\approx 1 \mathrm{R} \approx 1 \mathrm{rad}$.

The exposure received by sheltering and evacuation is always changing due to radioactive decay. A way to display the exposure that might be received can be seen in the cumulative dose graph shown in Figure 2, which demonstrates the total exposure (shelter dose + evacuation dose) with various departure times. In the example scenario depicted, one hour after the detonation, those in the shelter will have received a 42-rem dose, and departure at this time (1 hour) will result in an evacuation dose of an additional 89 rem, yielding a total exposure of 131 rem for shelter departure at 1 hour.

In this case, sheltering 12 hours results in a slightly higher total dose than a departure at 4 hours, however an early departure can result in significantly higher (potentially lethal) evacuation doses. Through the use of this graph, the total (shelter + evacuation) dose can be determined for any of the shelter departure times noted on the $x$-axis. Optimal evacuation time depends on building protection factor, fallout distribution, and evacuation-route doses. Unfortunately this information will not be known to most evacuees. This study aims to provide guidance to help first responders estimate a good time to evacuate with the limited information they have.

\subsubsection{Paths}

This document will refer to two types of paths. These paths are intended to be determined based on only detonation location and evacuation starting point.

- Radial: Refers to a path that simply heads away from the detonation point.

- Lateral: Refers to a path that goes perpendicular to the imaginary line connecting the detonation location and evacuation starting point. There are two possible lateral paths:

- The better lateral path has a smaller radiation dose.

- The worse lateral path has a larger dose. This is usually because it goes back into areas with heavier fallout or it takes longer to escape the fallout.

Radial and lateral paths may be distinguishable to responders who can approximate the detonation location and do not require information about cloud movement. As demonstrated later on, one of the lateral paths is often the best evacuation. Responders can identify lateral paths by taking a path perpendicular to the line that connects their location with the detonation location, as seen in Figure 3.

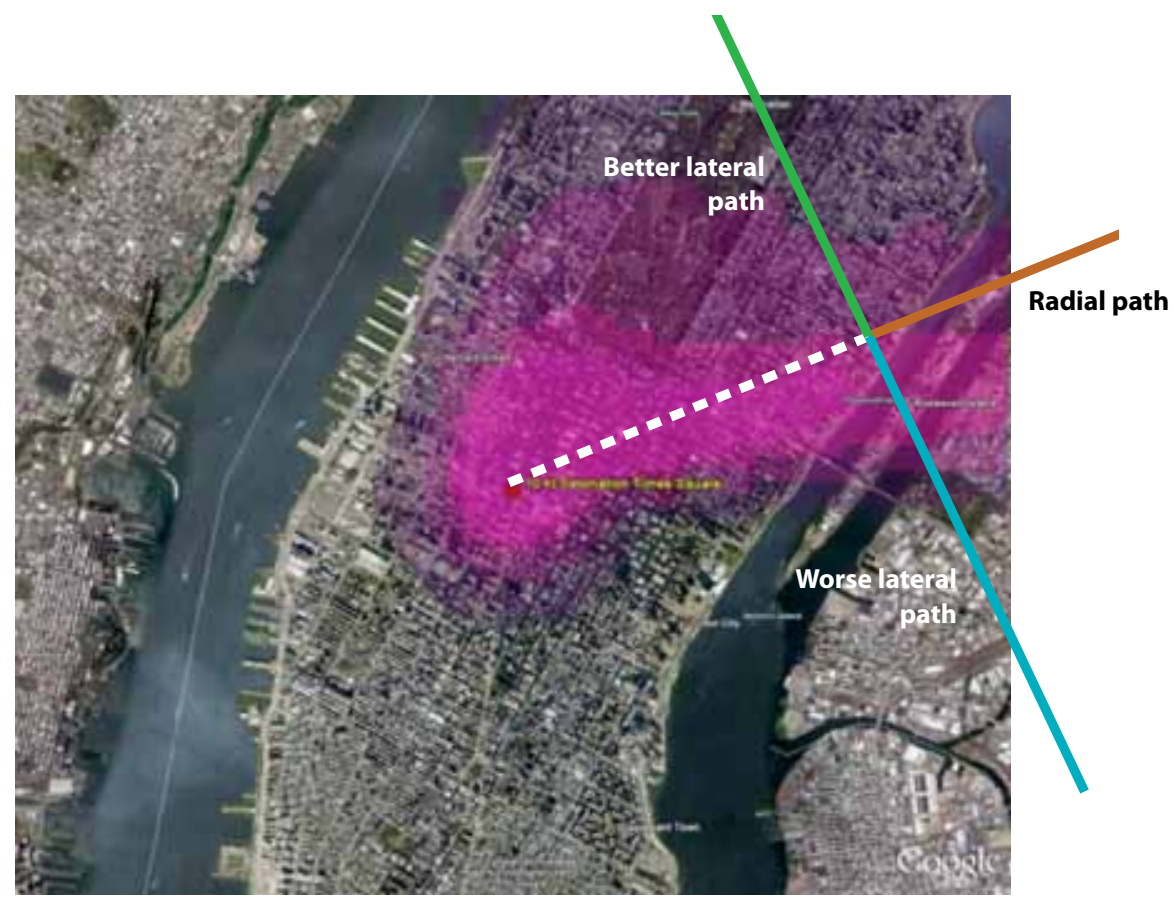

Figure3. Examples of lateral and radial evacuation paths. 


\subsection{Technical Approach}

\subsection{Overview}

The basis of this study was the comparison of the gamma radiation dose received during sheltering and the dose received during evacuation. The sheltered dose was calculated by finding the integrated dose over a specified time and then dividing by the protection factor. The evacuation dose was found by dividing the evacuation route into segments and adding up the dose received in each segment.

\subsection{Dataset Used}

The data used for this study was generated by the atmospheric models run by the National Atmospheric Release Advisory Center (NARAC) at Lawrence Livermore National Laboratory (LLNL). The data consists of radiation dose rates and integrated dose data for 100x100-meter cells. All the data analyzed was for a ground-level, 10-kt nuclear detonation at Times Square in New York City.

\subsection{Calculation of Sheltered Dose}

The sheltered dose was calculated based on the outside dose rate an hour after detonation $\left(d_{1}\right)$ and the 24-hour integrated dose $\left(D_{24}\right)$ from the NARAC data set. The fundamental equations used for dose calculations are shown below. The dose at any time can be found using the dose rate at one hour ${ }^{3}$ :

$$
d(t)=d_{1} t^{-1.2}
$$

where:

$d(t)=$ Gamma dose rate as a function of time $t$

$d_{1}=$ Gamma dose rate one hour after detonation

$t \quad=$ Time after detonation (hours).

To find the dose received over a given time period, the equation can be integrated:

$$
D(t)=\int_{t_{o}}^{t} d_{1} t^{-1.2} d t
$$

where:

$$
D(t)=\text { Gamma dose received from time }
$$$$
t_{o} \text { to } t
$$

The 1-hour dose rate and 24-hour integrated dose can be used to estimate the time of fallout arrival. This is done by manipulating the integrated dose equation:

$$
\begin{gathered}
D_{24}=\int_{t_{\text {arrival }}}^{24 \mathrm{hrs}} d_{1} t^{-1.2} d t \\
t_{\text {arrival }}=\left[24^{-0.2}+0.2\left(\frac{D_{24}}{d_{1}}\right)\right]^{-5}
\end{gathered}
$$

where:

$D_{24}=$ Gamma dose received from the time of cloud arrival until 24 hours after detonation

$t_{\text {arrival }}=$ Time the fallout cloud arrived over shelter.

The radiation dose received during sheltering was calculated by taking the integrated dose received outdoors and dividing it by the protection factor of the shelter:

$$
D_{\text {shltr }}(t)=\frac{1}{P F} \int_{t_{\text {arrival }}}^{t} d_{1} t^{-1.2} d t
$$

where:

$P F=$ The shelter's protection factor $D_{\text {shltr }}(t)=$ The total dose received by sheltering from the time of cloud arrival until time $t$.

\subsection{Calculation of Evacuation Doses}

Google Earth was used to model the various evacuation paths tested. After the determination of an evacuation path, the evacuation dose was calculated by copying the path from Google Earth to Excel. In Excel, the path's geographic data from Google Earth KML code was parsed and split into small segments. A custom function evaluated the distance between each segment. Another function determined in which grid cell the center of the segment was located. Once the segment was associated with the grid cell, the data for fallout radiation exposure for that cell was retrieved.

The dose received in each segment was found by using the integrated dose equation:

$$
D_{\text {segment }}=\int_{t_{o}}^{t_{f}} d_{1} t^{-1.2} d t
$$

where:

$D_{\text {segment }}=$ The dose received during a particular segment of the evacuation route

$t_{\alpha^{\prime}} t_{f} \quad=$ The times that travel through the segment was started and ended.

The total evacuation dose was calculated by adding up the dose received for each segment of the evacuation:

$$
D_{\text {evac }}=\sum D_{\text {segment }}
$$

where:

$D_{\text {evac }}=$ The total evacuation dose.

The evacuation dose for any start time was originally calculated by changing the start time to the beginning of the evacuation. For simplification, the evacuation dose at any time was calculated by using the following equation for times after one hour:

$$
D_{\text {evac }}(t)=D_{\text {evac at } 1 \mathrm{hr}} \cdot t^{-1.2}
$$

where:

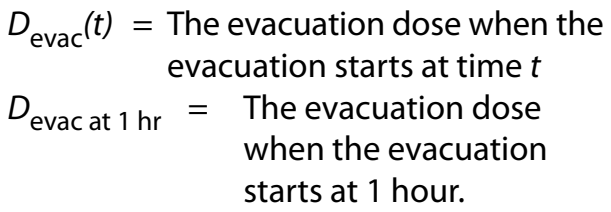

This simplification resulted in unreasonably high evacuation doses for evacuations before cloud arrival. The high evacuation 


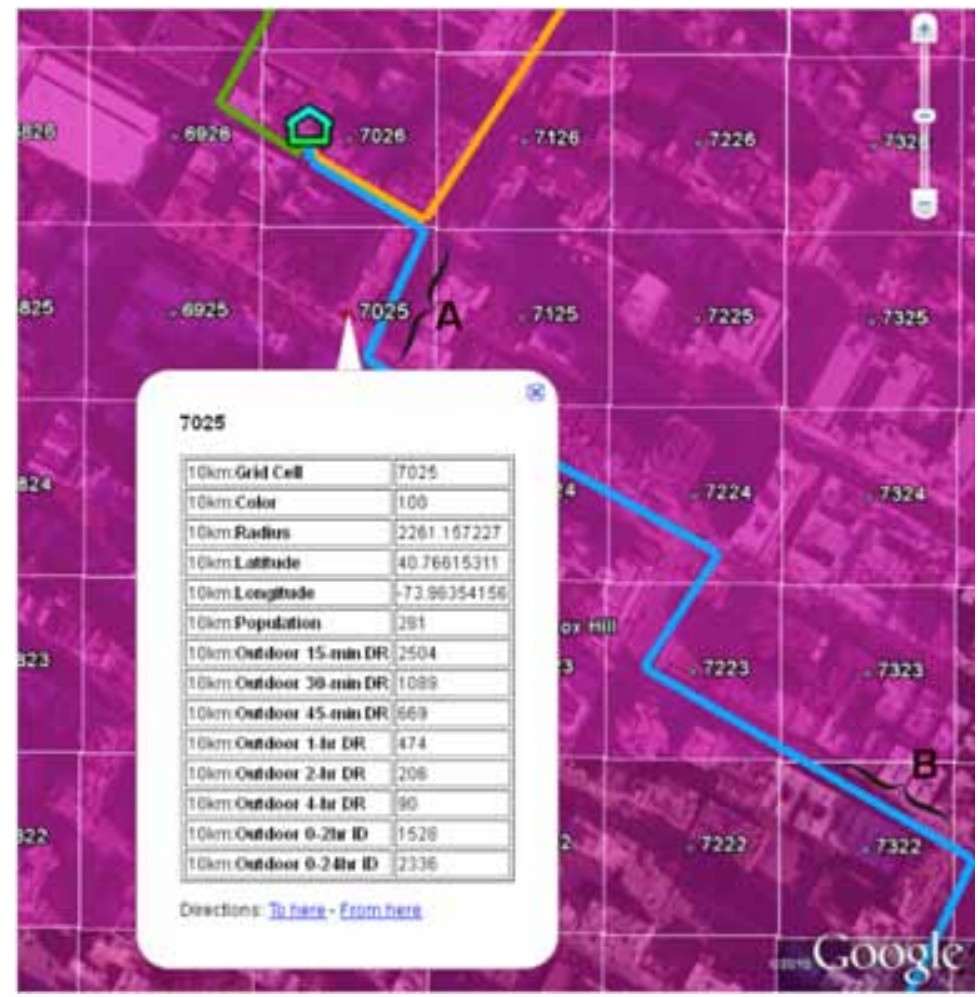

Figure 4 (left): An evacuation path passes through grid cells. Each grid cell has associated radiation dose data. Path segments $A$ and $B$ are labeled for reference to Figure 5 .

Figure 5 (below): Spreadsheet showing calculations for evacuation dose. Each line of the spreadsheet integrates the dose received for small segments of an evacuation path. The rows labeled $A$ and $B$ correspond to the segments illustrated in Figure 4.

Evacuation Path

\begin{tabular}{|c|c|c|c|c|c|c|c|c|c|}
\hline \multicolumn{2}{|c|}{ Blue } & \multicolumn{2}{|l|}{ (meters) } & (R/hr) & (R) & (hr) & min & \multirow{2}{*}{$\begin{array}{c}\mathrm{Hr} \\
\text { Time after }\end{array}$} & \multirow[t]{2}{*}{ rem } \\
\hline Latitude & Longitude & Distance & $\begin{array}{l}\text { Grid Cell } \\
\text { Number }\end{array}$ & $\begin{array}{l}\text { Outdoor } \\
\text { 1-hr Dh }\end{array}$ & $\begin{array}{l}\text { Outdoor o- } \\
24 \text { he io }\end{array}$ & $\begin{array}{l}\text { Cloud } \\
\text { Arrival }\end{array}$ & $\begin{array}{c}\text { Exposure } \\
\text { Time }\end{array}$ & & \\
\hline 40.7670 & -73.9638 & 11.051 & 7026 & 460.09 & 2241.91 & 0.130 & 0.2 & 1.00 & 169 \\
\hline 40.7669 & -73.9638 & 76.300 & 7026 & 46009 & 2241.91 & 0.130 & 15 & 103 & 11.48 \\
\hline 40.7666 & -73.9630 & 80.330 & 7025 & 473.95 & 2336.34 & 0.125 & 16 & 106 & 12.07 \\
\hline 40.7659 & -73.9634 & 57.470 & 7025 & 473.95 & 2336.34 & 0.125 & 11 & 1.08 & 6. 41 \\
\hline 40.7657 & -73.9628 & 57.470 & 7124 & 448.04 & 2213,64 & 0.124 & 11 & 109 & 7,79 \\
\hline 40,7654 & .73 .9622 & 57.470 & 7124 & 44804 & 2213.64 & 0.124 & 1.1 & 1.11 & 762 \\
\hline 40.7652 & -73.9616 & 57.470 & 7224 & 442.62 & 2168.46 & 0.128 & 1.1 & 1.13 & 7.38 \\
\hline 40.7649 & -73.9610 & 7.689 & 7223 & 36019 & 1777.13 & 0.125 & 1.6 & 1.16 & 7.93 \\
\hline 40.7644 & -73.9615 & 54.396 & 7223 & 360.19 & 1777.13 & 0.125 & 1.1 & 1.18 & 5.42 \\
\hline 40,7641 & -73.9610 & 54,396 & 7223 & 360.19 & 1777.13 & 0.125 & 11 & 1.19 & 532 \\
\hline 40.7639 & -73.9604 & 54.396 & 7322 & 231.42 & 1142.23 & 0.125 & 1.1 & 1.21 & 3.36 \\
\hline 40.7636 & -73.9599 & 54.396 & 7322 & 231.42 & 1142.23 & 0.125 & 11 & 1.23 & 3.30 \\
\hline 40.7634 & -73.9593 & 50.079 & 7322 & 231.42 & 114223 & 0.125 & 16 & 1.26 & 4.75 \\
\hline 40.7627 & -73.9597 & 78.340 & 7321 & 152.00 & 755.64 & 0.122 & 1.6 & 1.28 & 2.98 \\
\hline 40.7621 & .73 .9601 & 54.839 & 7320 & 9072 & 454.41 & 0.119 & 1.1 & 1.30 & 122 \\
\hline 40.7617 & -73.9597 & 54.839 & 7320 & 9072 & 454.41 & 0.119 & 1.1 & 132 & 1.20 \\
\hline 40.7613 & -73.9593 & 54.839 & 7419 & 33.25 & 165.56 & 0.121 & 1.1 & 134 & 0.43 \\
\hline 40.7609 & -73.9589 & 54.839 & 7419 & 33.25 & 16556 & 0.121 & 11 & 1.36 & 0.42 \\
\hline 40.7605 & $-73,9584$ & 70.240 & 7419 & 33.25 & 16556 & 0.121 & 14 & 1.38 & 0.53 \\
\hline 40,7600 & -73.9589 & 86.017 & 7418 & 11.68 & 58.34 & 0.120 & 17 & 1.41 & 0.22 \\
\hline 40.7593 & -73.9593 & 51.268 & 7417 & 2.71 & 1356 & 0.119 & 10 & 2.43 & 0.03 \\
\hline 40,7588 & -73.9591 & 66.253 & 7417 & 2.71 & 13.56 & 0.119 & 1.3 & 1.45 & 0.04 \\
\hline 40.7586 & -73.9584 & 66.253 & 7516 & 0.37 & 2.85 & 0.115 & 1.3 & 1.47 & 0.01 \\
\hline 40.7583 & -73.9577 & 66.254 & 7516 & 037 & 1.85 & 0.115 & 1.3 & 1.49 & 0.01 \\
\hline 40.7580 & -73.9570 & 66.254 & 7616 & 103 & 5.13 & 0.120 & 1.3 & 1.51 & 0.01 \\
\hline 40.7577 & -73.9564 & 66.254 & 7616 & 1.03 & 5.13 & 0.120 & 1.3 & 1.54 & 001 \\
\hline 40,7574 & -73.9557 & 66.254 & 7715 & 0.53 & 270 & 0.115 & 1.3 & 1.56 & 0.01 \\
\hline 40.7571 & -73.9550 & 66.255 & 7815 & 0.29 & 1.47 & 0.116 & 1.3 & 1.58 & 000 \\
\hline
\end{tabular}

doses are due to the fact that the application of the power rule for times before cloud arrival does not take into account that the cloud has not arrived for many of the segments of the path. This is compounded because as time approaches zero, the power rule returns doses approaching infinity. Cloud arrival time was estimated based on the NARAC calculated integrated exposure for the evacuation starting location and used in the development of the shelter/ evacuation time optimization graphs.

For times after an hour, it was found that the simplification provided results slightly below (a few rem) what it would have been had the entire path been evaluated for a later start time. This simplification has been used because this analysis focused on evacuations occurring after cloud arrival.

\subsection{Data Analysis}

Data was collected in two ways. Most of the data collection consisted of evaluating computer-generated lateral and radial paths. These paths do not follow streets or avoid obstacles but simply take paths perpendicular to the line from the detonation location to the shelter. Using this automated method, two lateral paths and a radial path were evaluated for over 800 different starting points in five different weather patterns.

To check the automatically generated paths against more realistic paths, lateral and radial evacuation paths were drawn by hand to follow streets and avoid obstacles. Two lateral paths and a radial path were drawn for each of seven locations. These paths were tested against different fallout patterns by evaluating the evacuation dose for the paths using datasets from different months of the year. In total, this provided 45 different scenarios for comparison. 
The data was used to verify that dose rate changes as the responders move around can be used as an indicator of evacuationroute quality. For example, for a responder monitoring dose rates over the first few minutes of an evacuation, an increasing dose rate would likely indicate that they are on the wrong path and would likely receive a higher exposure than just remaining in the shelter. A challenge

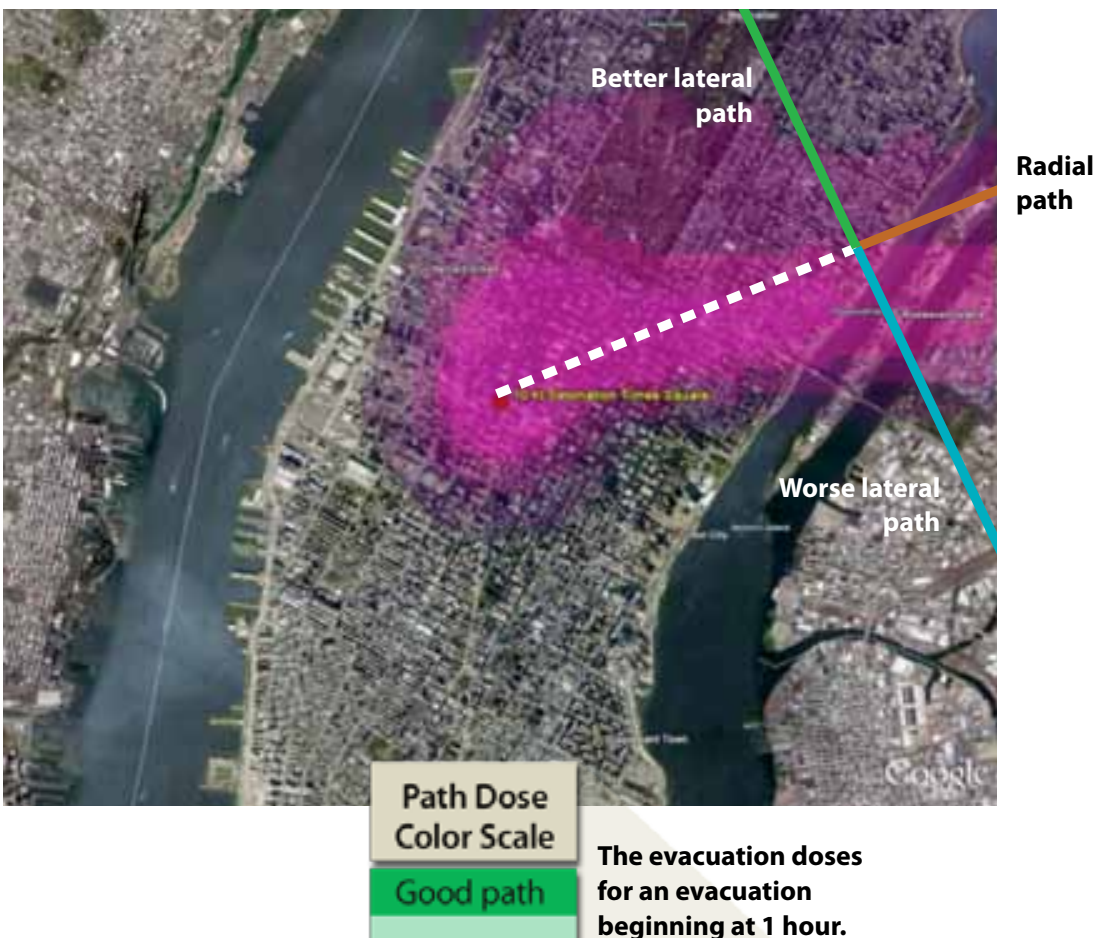

comes from the fact the dose rates are falling off rapidly everywhere as the fallout decays, so the assessment in the following pages validates that dose-rate measurements will likely be a reasonable indicator of the correct evacuation path. An example of the automatically generated data can be seen below.

The change in radiation rate measured in the first four minutes of a given path.
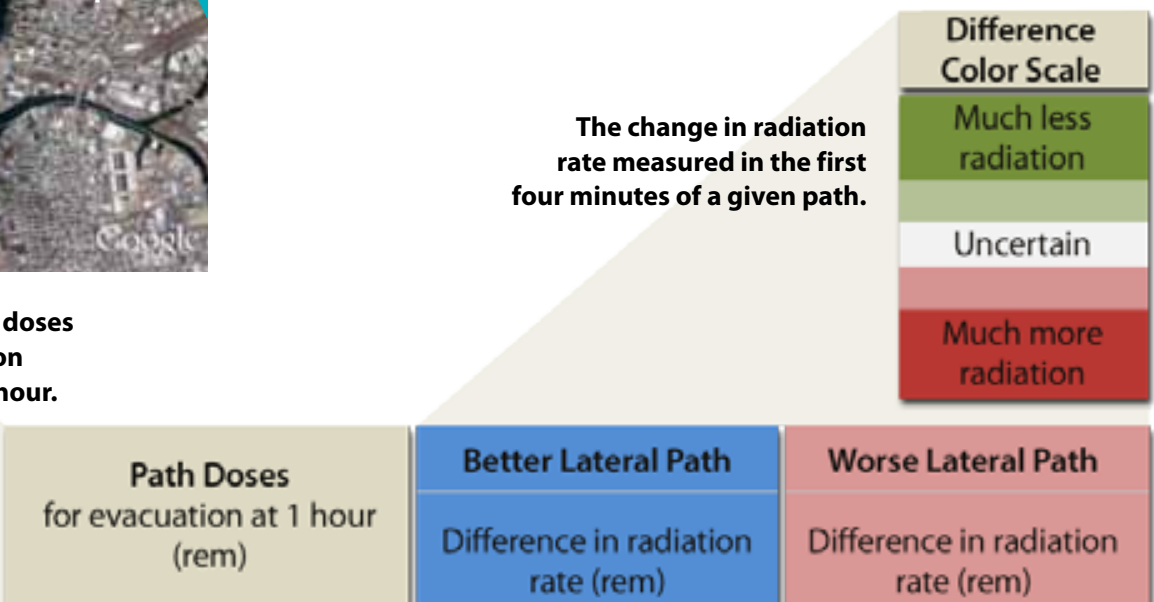

\begin{tabular}{|c|c|c|c|c|c|}
\hline $\begin{array}{c}\text { Better Lateral Path } \\
\text { Difference in radiation } \\
\text { rate (rem) }\end{array}$ & \multicolumn{2}{|c|}{$\begin{array}{c}\text { Worse Lateral Path } \\
\text { Difference in radiation } \\
\text { rate (rem) }\end{array}$} \\
\hline $0: 02$ & $0: 03$ & $0: 04$ & $0: 02$ & $0: 03$ & $0: 04$ \\
\hline 0 & 1 & 2 & -4 & -3 & -8 \\
\hline 11 & 12 & 22 & 2 & 5 & 7 \\
\hline 66 & 69 & 129 & -30 & -25 & -50 \\
\hline 29 & 35 & 69 & -6 & -18 & -11 \\
\hline
\end{tabular}

The location of the starting point for the evacuation identified by grid cell as seen in Figure 4.

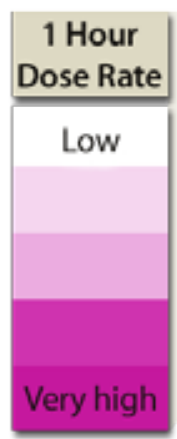

\begin{tabular}{|c||c|c|c|c|c|}
\hline Box & $\begin{array}{c}\text { 1 hour DR } \\
\text { (rem) }\end{array}$ & $\mathbf{2 4}$ hour ID & Better & Worse & Radial \\
\hline 8439 & 32 & 114 & 11 & 73 & 40 \\
\hline 7434 & 78 & 254 & 24 & 96 & 61 \\
\hline 8218 & 185 & 903 & 11 & 96 & 510 \\
\hline $\mathbf{8 0 2 4}$ & $\mathbf{2 7 9}$ & 1209 & 57 & 61 & $\mathbf{2 4 2}$ \\
\hline
\end{tabular}

Figure 6. Example: If an evacuation starts an hour after detonation from box 8024 . The responder's meter reads $279 \mathrm{rem} / \mathrm{hr}$ outside. In the first few minutes of the evacuation attempt, the better lateral path will result in decreasing radiation readings (a decrease of $69 \mathrm{rem} / \mathrm{hr}$ after 4 minutes). Evacuation using the worse

The dose rate at the starting point one hour after detonation. lateral evacuation path will result in increased radiation reading (an increase of $11 \mathrm{R} / \mathrm{hr}$ after 4 minutes). However, in this example the total dose received using of the worse lateral path $(61 \mathrm{rem})$ is not that significantly different from the better lateral path dose of $57 \mathrm{rem}$. Even though the Radial evacuation path will also demonstrate decreasing radiation levels during evacuation, taking the this path path it would result in the highest dose of 242 rem. 

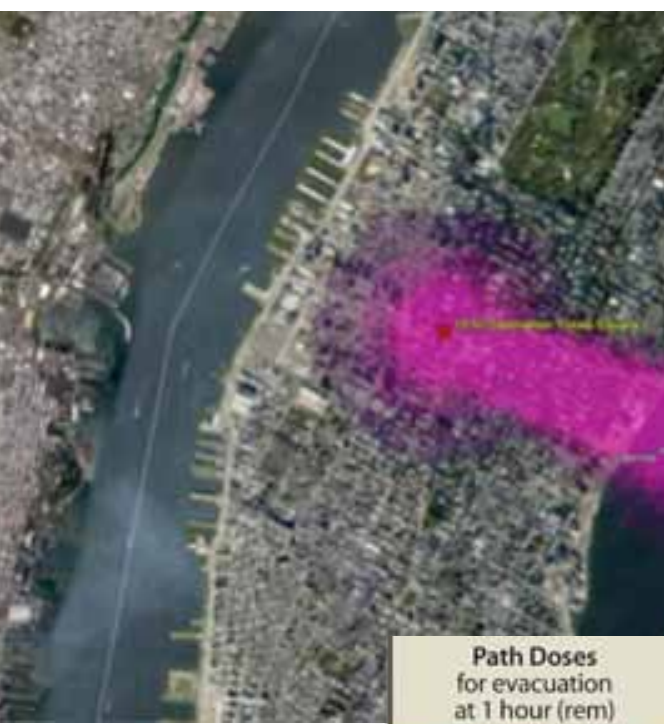

V4985

$78 \times x+3 y$

Path Doses for evacuation at 1 hour (rem)

Better Lateral Path Difference in radiation rate (rem)

\begin{tabular}{l|l|l|l|l}
\hline $\mathrm{Bo}$ & $-1 \mathrm{hr}$ & 1 & $24 \mathrm{hr}$ \\
\hline
\end{tabular}

4618

6501

4511

6114

7396

8092

7310

9186

4909

8888

4817

8889

3387

4713

7199

8493

5110

7001

9988

8992

9993

9392

9494

7699

8700

7804

8398

8099

7202

6805

5712

5611

5212

162

737

372

660
Bett * Wor * Radi * $0.02 * 0.03 \times 0.04 * 0.02 * 0.03 * 0.04 *$

\begin{tabular}{l|l|c|c|ccc}
224 & 1 & 13 & 1 & 8 & 14 & 14 \\
119 & 1 & 254 & 1 & 18 & 18 & 21 \\
258 & 2 & 6 & 1 & 8 & 8 & 14
\end{tabular}

258

198

104

230

282

906

598

1675

826

1136

2789

1622

1547

1627

1782

2065

2303

2773

2494

3509

3423

3799

4488

7787

14076

20328

30526

\begin{tabular}{|c|c|ccc|ccc|}
\hline 6 & 1 & 8 & 8 & 14 & -5 & -10 & -9 \\
\hline 297 & 373 & 22 & 22 & 25 & -132 & -128 & -519 \\
\hline 210 & 2 & 23 & 24 & 33 & -35 & -33 & $-1-4$ \\
187 & 3 & 22 & 23 & 33 & -38 & -98 & -95 \\
\hline 226 & 57 & 34 & 35 & 43 & -77 & -240 & -233 \\
\hline 147 & 4 & 28 & 29 & 47 & -34 & -32 & -34 \\
\hline 126 & 5 & 34 & 51 & 52 & -56 & -53 & -213 \\
\hline 158 & 7 & 42 & 43 & 65 & -44 & -41 & -89 \\
\hline 51 & 5 & 39 & 40 & 60 & -58 & -55 & -144 \\
\hline 160 & 12 & 54 & 93 & 94 & -47 & -43 & -99 \\
\hline 148 & 17 & 49 & 83 & 84 & -52 & -47 & -113 \\
\hline 17 & 8 & 29 & 69 & 71 & 16 & 19 & 46 \\
\hline 230 & 11 & 98 & 100 & 139 & -147 & -140 & -368 \\
\hline 173 & 27 & 87 & 91 & 151 & -80 & -73 & -171 \\
\hline 383 & 21 & 195 & 197 & 241 & -724 & -702 & -2127 \\
\hline 253 & 23 & 177 & 180 & 255 & -264 & -576 & -556 \\
\hline 121 & 80 & 58 & 65 & 131 & -7 & 2 & -13 \\
\hline 149 & 55 & 92 & 162 & 166 & -71 & -126 & -115 \\
\hline 102 & 196 & 45 & 83 & 91 & -6 & 4 & 32 \\
\hline 121 & 99 & 95 & 103 & 167 & -29 & -38 & -27 \\
\hline 97 & 172 & 37 & 48 & 104 & 40 & 51 & 100 \\
\hline 191 & 67 & 223 & 380 & 385 & -189 & -171 & -348 \\
\hline 147 & 312 & 148 & 282 & 289 & -80 & -100 & -85 \\
\hline 185 & 402 & 263 & 474 & 481 & -155 & -237 & -214 \\
\hline 128 & 161 & 135 & 149 & 271 & -36 & -18 & 11 \\
\hline 148 & 150 & 177 & 192 & 344 & -49 & -42 & -22 \\
\hline 208 & 95 & 352 & 365 & 612 & -217 & -192 & -300 \\
\hline 197 & 200 & 459 & 493 & 910 & -119 & 39 & 71 \\
\hline 277 & 632 & 1095 & 1117 & 1781 & -571 & -511 & -218 \\
\hline 182 & 391 & 793 & 840 & 1851 & 483 & 1554 & 1583 \\
\hline 312 & 235 & 1730 & 1763 & 2792 & -582 & 499 & 560 \\
\hline
\end{tabular}

\subsubsection{July 14th Data}

This scenario has a very simple fallout pattern. The simplicity of the pattern makes finding a good lateral path much easier. In this data, it is seen that one lateral path is often significantly better than the other. This is because one lateral path usually leads away from the plume and the other heads back into it. In every case, the better path is well indicated by rapidly falling gamma dose rates in the first four minutes of evacuation. For places where both evacuation paths have decreasing dose rates in the first minutes, they both have similar total exposures. Taking the route with more rapidly decreasing dose rates will be a good route every time.

Figure 7. Fallout exposure patterns. 


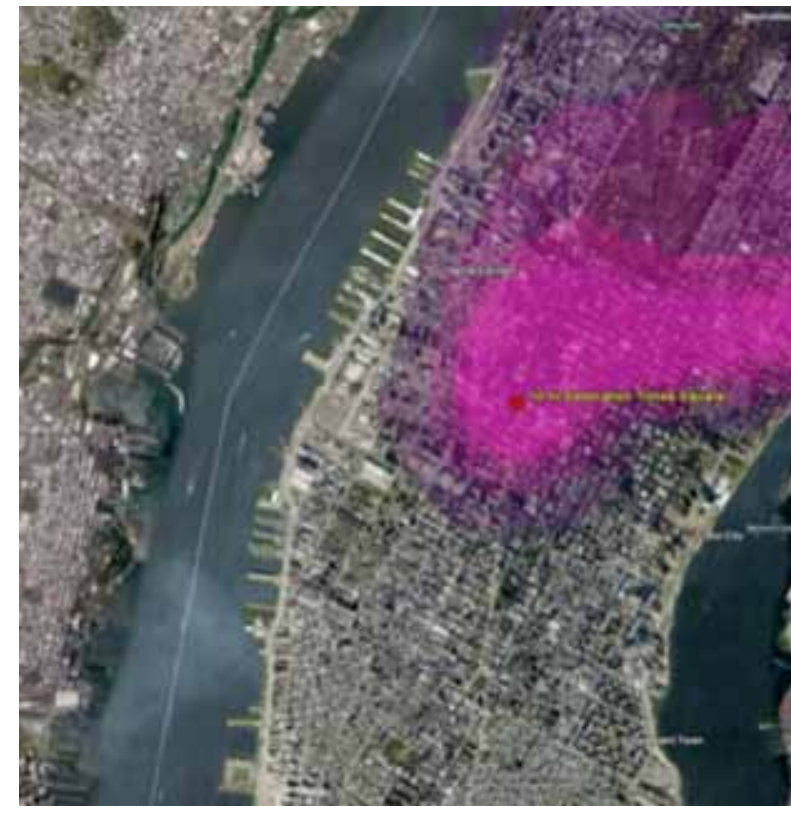

Figure 8. For Box 4617 , the worse path's radiation rates actually decrease more rapidly in the first minutes. In this case, the two paths here both have very similar total exposures.

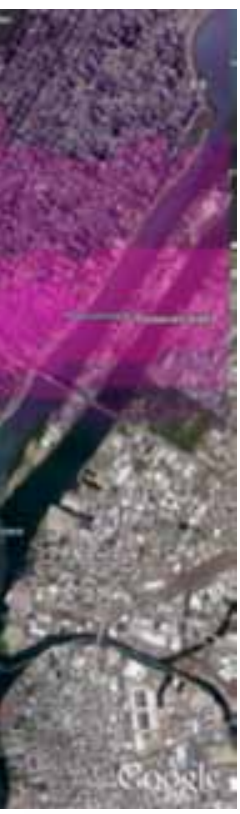

\subsubsection{December 14th Data}

This fallout pattern was influenced by weaker upper atmospheric winds and a greater wind shear at lower levels, creating a fallout pattern that is more spread out. For the points that fell in areas with less fallout, such as in the northeastern part of the map, the difference between a good route and a bad route became much less certain. This can be seen in the first 13 rows of data. Despite the increased complexity of this pattern, decreasing radiation rates in the first minutes of evacuation still usually indicated the better path.

\begin{tabular}{|c|c|c|c|c|c|c|c|c|c|c|c|}
\hline \multicolumn{3}{|c|}{ 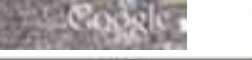 } & \multicolumn{3}{|c|}{ for Evacuation at 1 hour (remi) } & \multicolumn{3}{|c|}{$\begin{array}{l}\text { Daffereece in Radiation Rate } \\
\text { [uem] }\end{array}$} & \multicolumn{3}{|c|}{$\begin{array}{l}\text { Defference in Radiatian Rate } \\
\text { (rem) }\end{array}$} \\
\hline $\operatorname{Box}$ & $\begin{array}{l}1 \mathrm{hr} \\
\text { Of }\end{array}$ & $24 \mathrm{hr}=\mathrm{sb}$ & Better & Worse & Radal & 0,62 & 0.03 & 0.04 & 0.02 & 0.03 & 004 \\
\hline 9850 & 20 & 60 & 5 & 54 & 16 & 5 & 5 & 7 & 1 & 3 & 4 \\
\hline 5241 & 25 & 69 & 5 & 826 & 3 & 4 & 4 & 5 & -4 & -3 & -11 \\
\hline 9545 & 27 & 85 & 7 & 59 & 25 & 7 & 7 & 11 & -2 & -2 & 1 \\
\hline 7347 & 29 & 121 & 7 & 88 & 17 & 6 & 7 & 7 & -6 & -5 & -8 \\
\hline 8142 & 32 & 121 & 10 & 78 & 32 & 6 & 10 & 10 & 1 & 2 & 1 \\
\hline 8536 & 47 & 160 & 14 & 75 & 5s: & 4 & 11 & 12 & 3 & -2 & .5 \\
\hline 7636 & 53 & 181 & 13 & 92 & 53 & 6 & 7 & 15 & 2 & -3 & -1 \\
\hline 6144 & 54 & 157 & 10 & 148 & 12 & 11 & 12 & 20 & -2 & -1 & -2 \\
\hline 6643 & 58 & 181 & 13 & 116 & 20 & 9 & 20 & 21 & -2 & -5 & -4 \\
\hline 9535 & 60 & 204 & 15 & 65 & 64 & 11 & 12 & 19 & -6 & -10 & -9 \\
\hline 7239 & 65 & 209 & 18. & 98 & 36 & 10 & 11 & 17 & -3 & -6 & -4 \\
\hline 7339 & 65 & 211 & 17 & 94 & 37) & 7 & 15 & 16 & $s$ & 6 & 7 \\
\hline 9133 & 74 & 261 & 19. & $\pi$ & 75 & 8 & 21 & 23 & 0 & 2 & -20 \\
\hline 6735 & 90 & 267 & 27 & 122 & 47 & 6 & 8 & 14 & -8 & -6 & 19 \\
\hline 7032 & 102 & 329 & 33 & 110 & 73 & 13 & 15 & 18 & -9 & -19 & -16 \\
\hline 9318 & 105 & 502 & t & 79 & 471 & 30 & 55 & 56 & -21 & -18 & -47 \\
\hline 6534 & 111 & 334 & 31 & 126 & 49 & 14 & 16 & 24 & -9 & -11 & -14 \\
\hline 9030 & 127 & 481 & 26. & 69 & 109 & 29 & 31 & 57 & -7 & -4 & -19 \\
\hline 8428 & 159 & 623 & 32 & $n$ & 134 & 37 & 40 & 58 & -34 & -20 & 43 \\
\hline 5532 & 161 & 505 & 31 & 349 & 26 & 29 & 54 & 56 & -16 & +12 & 40 \\
\hline 5330 & 192 & 631 & 34 & fis & 23 & 46 & 49 & $\pi$ & -30 & 25 & 43 \\
\hline 4617 & 228 & 1250 & 34 & 42 & 9 & 6 & 11 & 28 & 26 & 51 & 55 \\
\hline 8721 & 248 & 1150 & 25 & $n$ & 384 & 41 & 45 & 95 & -9 & -3 & -16 \\
\hline 7025 & 259 & 1061 & 61 & 95 & 174 & 58 & 62 & 98 & 37 & -30 & -76 \\
\hline 8024 & 279 & 1209 & 57 & 61 & 242 & 29 & 35 & 69 & -6 & -10 & -11 \\
\hline 5726 & 380 & 1346 & 76 & 239 & 90 & 67 & 74 & 127 & $-3 x$ & 28 & -76 \\
\hline 5924 & 407 & 1538 & 97 & 169 & 152 & 51 & 69) & 110 & -45 & 35 & -91 \\
\hline 7521 & 470 & 1964 & 45 & 93 & 380 & 70 & 78 & 137 & 0 & 9 & 59 \\
\hline 6919 & 430 & 2120 & 35 & 124 & 515. & 101 & 108 & 206 & 24 & -14 & 6 \\
\hline 6719 & 519 & 2550 & 44. & 132 & 594 & 109 & 119 & 229 & -7 & 5 & 60 \\
\hline
\end{tabular}




\subsection{Trends in Doses}

Figure 9 represents the better lateral-path evacuation dose plotted against the outside dose rate at the evacuation starting point. The automatically generated data is represented by dots that vary by color for different fallout patterns. The hand-drawn evacuation routes that avoid obstacles and follow streets are represented by the triangles. Generally, as the outdoor rate increases, the evacuation dose increases. It also appears that evacuation dose increases linearly at first and then spreads as starting point dose rate increases. The trend also varies by fallout pattern. Note that for the April and November fallout, the evacuation dose rises very quickly and linearly in the beginning. This is because the fallout pattern for these tests had a large spread area of low radiation that must be crossed to evacuate. This was not the case for the July, October, or December fallout pattern, in which most of the radiation is concentrated in the fallout and is more quickly and easily escaped.

\subsection{Estimation of Evacuation Dose Using Outdoor Rate}

In general, places with higher dose rates had higher evacuation doses. This trend has been used to estimate the maximum likely evacuation dose for the better lateral path based on outdoor dose rate at the evacuation starting point. As seen in Figure 9, there is quite a bit of spread, and the line representing this estimation does not accurately predict evacuation doses given the starting-point dose rate. The purpose of this line is to estimate the maximum likely evacuation dose. For this reason the line was drawn above $78 \%$ of the data points. The equation of the line to predict maximum likely better evacuation dose is below:

$$
D_{\text {evac at } 1 \mathrm{hr}}(d)=3.65 \times 10^{-9} d^{3}-3.4
$$$$
\times 10^{-5} d^{2}+0.1122 d+40
$$
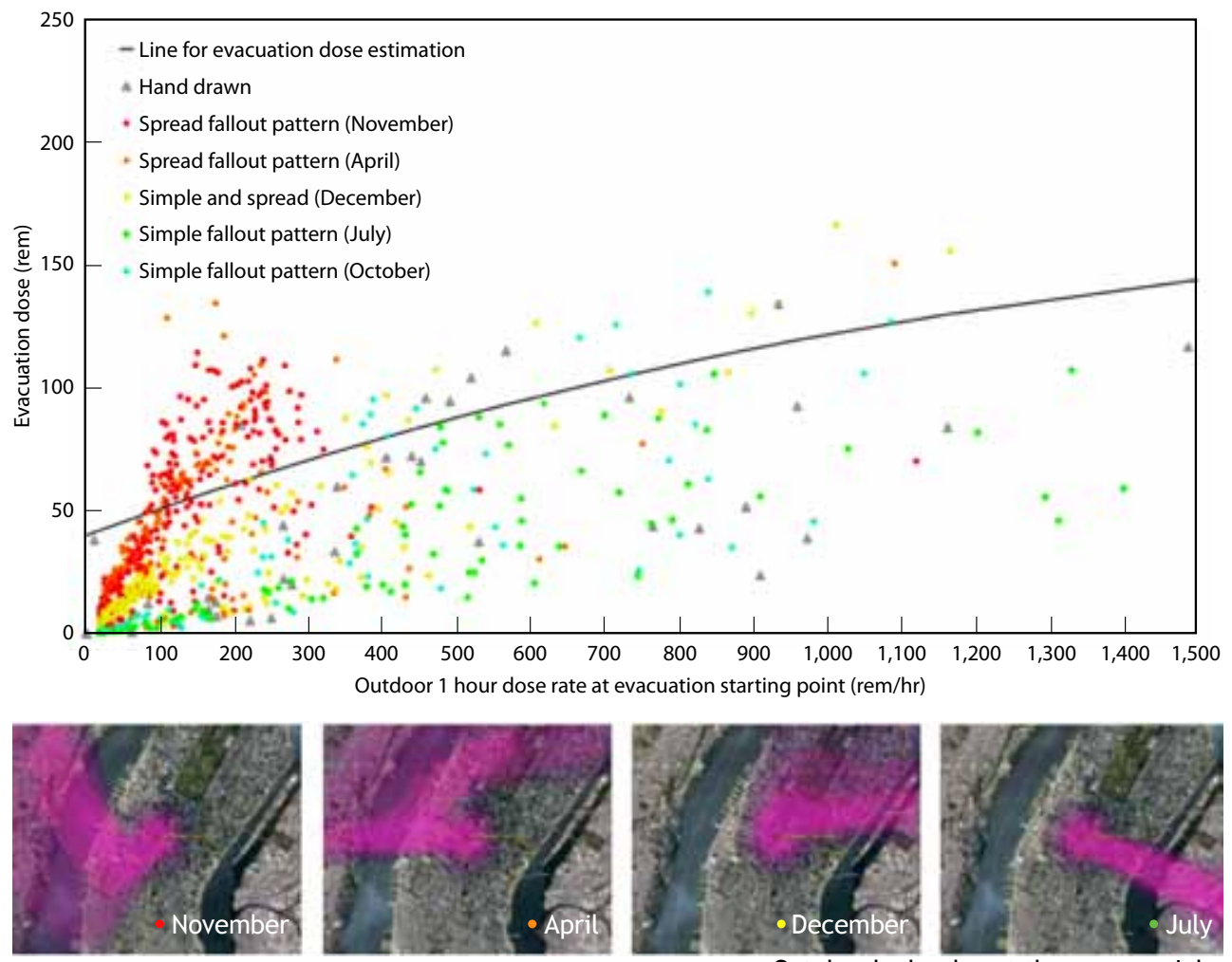

October looks almost the same as July.

Figure 9. Evacuation dose increases as dose rate at starting point increases.

Where:
$D_{\text {evac } 1 \mathrm{hr}}(t)=$ The evacuation dose for a better lateral path evacuation starting an hour after detonation (rem)
$d=$ The gamma dose rate at the evacuation starting point one hour after detonation.

This equation can be modified to estimate the evacuation dose for an evacuation starting at any time, as seen below:

$D_{\text {evac }}\left(d_{1}, t\right)=\left(3.65 \times 10^{-9} d^{3}-3.4\right.$

$\left.\times 10^{-5} d^{2}+0.1122 d+40\right) t^{-1.2}$

\subsection{Calculation of Recommended Evacuation Times}

Recommended evacuation times were calculated by finding the time at which the total dose (shelter + evacuation) was a minimum, as demonstrated at one hour for Figure 1. The total dose was calculated as the sum of the sheltered dose until evacuation began and the evacuation dose:

$D_{\text {total }}\left(t, d_{1}, P F\right)=D_{\text {shltr }}\left(t, d_{1}, P F\right)+D_{\text {evac }}\left(t, d_{1}\right)$

The value for total dose is found by substituting the equations for sheltered dose and estimation of the maximum likely evacuation dose at any time:

$$
\begin{aligned}
& D_{\text {total }}\left(t, d_{1}, P F\right)=\int_{t_{\text {arrival }}}^{t} \frac{d_{1}}{P F} d t+\left(3.65 \times 10^{-9} d^{3}\right. \\
& \left.-3.4 \times 10^{-5} d^{2}+0.1122 d+40\right) t^{-1.2}
\end{aligned}
$$


Figure 10 in the Results section was generated by iterating the equation above using different time values to find the time at which the total dose is a minimum provided the Responder can determine the best lateral evacuation path.

\subsection{Limitations, Assumptions, and Sources of Error}

The purpose of this study was to provide guidance to aid responders in decision making without the aid of advanced computer models or subject matter experts. Because detailed technical information may not be available to first responders at the time evacuation decisions are made, the results of this study are a rough guide as to what they should do. Because the results of this guide are general to different scenarios and different cases, it is expected that, in some cases, following the recommendations of this document will be worse than doing nothing at all or making uninformed decisions. However, for the cases examined, the strategy explained in this document is better than evacuation after 12 hours $^{*}$ more than $90 \%$ of the time.

\subsubsection{Weather and Scenario Bias}

A large source of bias in the results is the limited dataset used for analysis and conclusions. The data used consisted of fallout effects for 12 PM and 8 PM detonations at Times Square taken the 14th of each month in 2009. Although many fallout patterns likely resemble those used in this study, it is suspected that variation in time and space is important. A different detonation location with different prevailing winds and climate will have a different set of fallout patterns. Also, even detonations in Times Square could vary not only by time of year, but also by time of day, which was not considered in this study. In summary, the data used to make this analysis does not accurately represent a random set of fallout patterns for a detonation at any location or at any time of day. A statistical study of the probability of different patterns would be useful in understanding how to apply these results to any locale. Another limitation of this work is that it considered only ground-level detonations with a 10-kt yield. The effect of larger or smaller yields and different detonation altitudes has not been considered here.

\footnotetext{
* 12 to 24 hours is the current federal guidance and should be the default strategy if the evacuee does not have high range radiation dose rate instruments.

\subsubsection{Sources of Error}

Although many experiments have been conducted with nuclear weapons, there is no actual experimental data regarding the effects of a low-yield nuclear device at ground level in an urban environment. For this reason, this entire study was performed using data from models generated by NARAC. Because the data used for this study was generated by a model and not by actual experimentation, it is difficult to be certain how accurate the results are.

The calculation of exposure along segments of an evacuation route used the one-hour dose rate for whichever grid cell contained its midpoint. This approximation was probably not a large source of error. Other small sources of error include distance-measurement error from using latitude and longitude.

\subsubsection{Other Assumptions}

Calculation of evacuation paths assumed outdoor exposure and as such did not take into account exposure-reducing actions such as moving through buildings or subways. Path calculation assumed a steady, fast walking speed of $3 \mathrm{~km} / \mathrm{hr}$ (1.8 mph) and did not make any account for bad path discovery. The automatically generated data did not account for obstructions of any type. 


\subsection{Results}

The correlation between outside dose rate and evacuation dose was used to develop charts that can guide evacuation timing.

First responders with high-range radiationmeasurement capability and knowledge of their shelter's protection factor can use Figure 10 to find their recommended evacuation time.

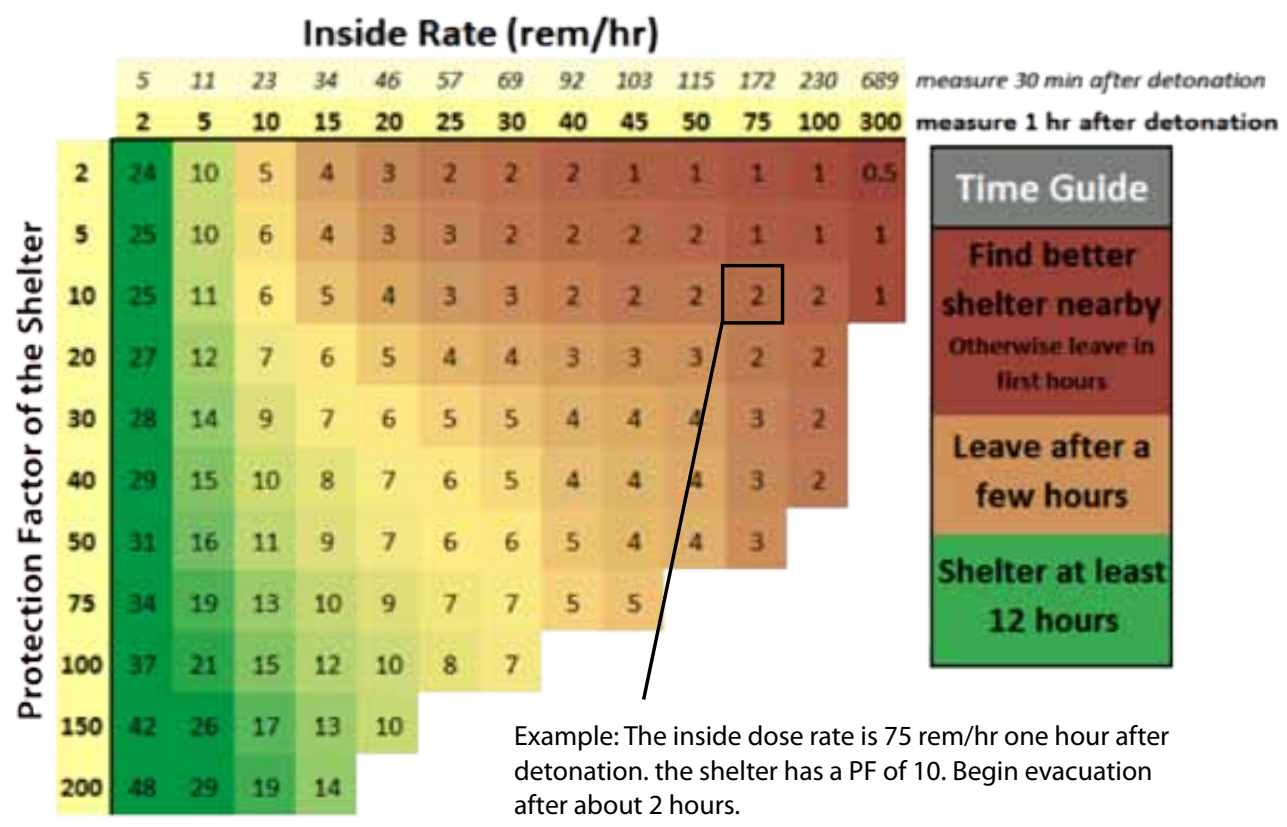

Figure 10. Evacuation time can be determined using protection factor and the dose rate measured inside.

\section{Inside Rate (rem/hr)}

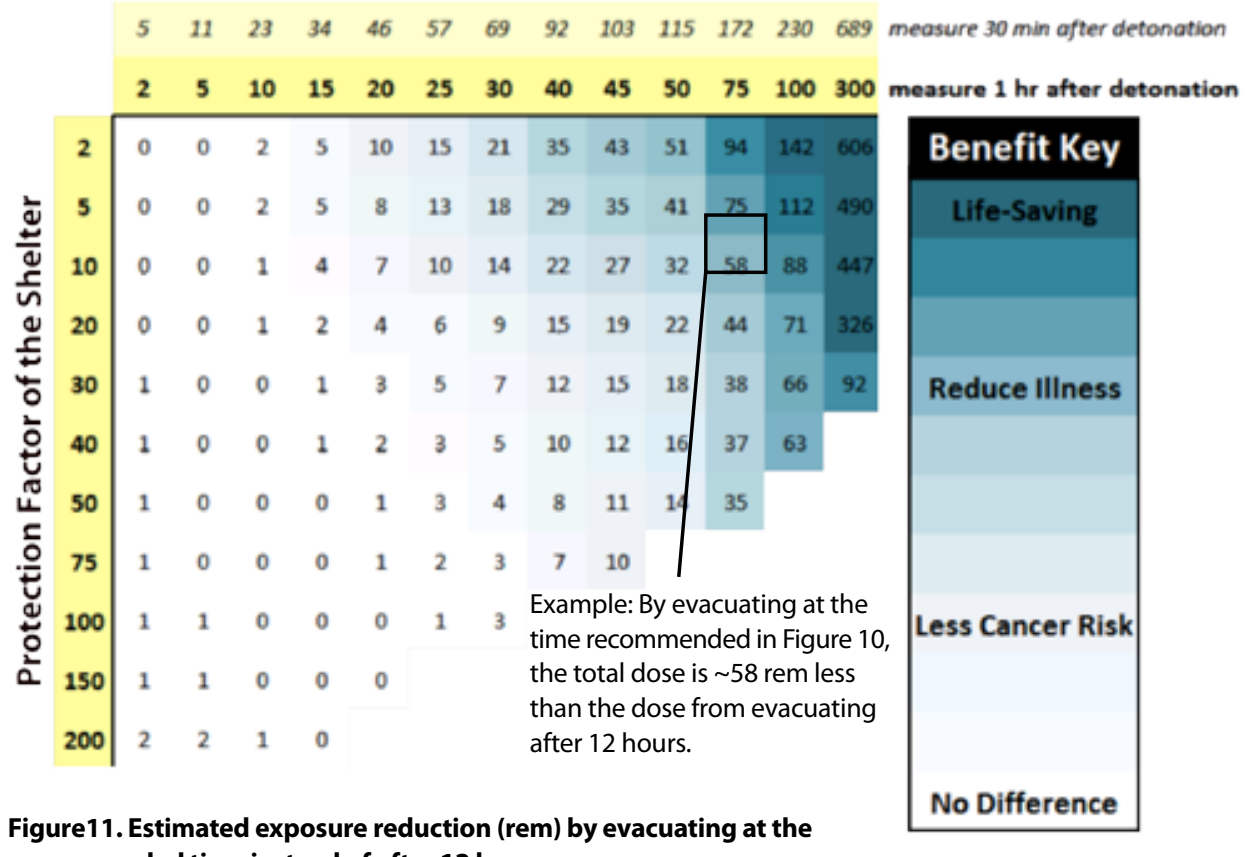

Figure 10 was generated by finding the time at which the total dose is a minimum. This was done by calculating sheltered dose and estimating evacuation dose as described in the methods section. The values in the figure have been rounded to the nearest hour to improve readability and to express uncertainty. For the data analyzed, the estimation of evacuation dose was conservative. This means that although in many cases the best time to evacuate may be sooner, a later time was used. This is an attempt to allow for error and make certain that those who take an evacuation route with a slightly more than expected dose will not be put in danger.

Although the estimate for evacuation dose was made slightly conservative, it is not recommended to evacuate at the above listed time for any evacuation path. Evacuation at the above listed time reduces dose only when a good path is taken. How to determine and monitor a good path is detailed in Section 3.2, "Guidance for Responders."

It is important to know the benefit of evacuating early compared to waiting 12 hours before evacuation. The first benefit is that first responders can be supporting response operations rather than sheltering in their firehouses. Their radiation-monitoring equipment can help them to find a safe route, which can often result in a lower exposure for an early evacuation. Another benefit of evacuating at the recommended time is reduced exposure. Figure 11 shows the benefit (in dose reduction) of optimal shelter departure time compared to a 12 -hour shelter departure. The table uses the same format as Figure 10 to allow for comparison. 


\subsection{Findings}

In the course of analysis, a number of interesting points were discovered.

- The evacuation dose for the better perpendicular path can be roughly estimated using the outdoor dose rate. This correlation makes time of evacuation guidance possible without measurements and models of the entire plume.

- The time of cloud arrival (and distance from detonation) was found to have no impact on the optimal shelter departure times after its arrival.

- It was observed that the better lateral path does not always pass through areas of decreasing intensity. However, the better lateral path is usually indicated by decreasing radiation rates, which should be used to determine best path.

- Paths that reach safe dose rates in less than $750 \mathrm{~m}$ were found to have very low dose rates every time.

\subsection{Guidance for Responders}

\subsubsection{Choosing When to Depart your Shelter}

Determining when to evacuate depends on shelter quality, measured radiation rates, and the ability to choose a good path. You will probably be able to identify a good path if any one of the following is true:

- Someone with a reliable model or measurements of fallout has told you which way to go.

- You can see where the fallout cloud is and can easily find a lateral path to escape it.

- You know of a radiation-free place that is within 15 minutes of your current location.
- You see a benefit (you need to exit either to reduce exposure or to be available to respond elsewhere) to early evacuation and can find an unobstructed lateral path where the radiation rate generally decreases.

If you are sure you can find a good path, you can estimate a good time to evacuate by using Figure 3. To use this tool, you will need to know your shelter's protection factor and the radiation rate indoors 30 minutes or one hour after detonation. If you are unsure about any of the above, it is recommended that you follow the most recent planning guidance for uninformed sheltering and evacuation.

\subsubsection{Taking a Better Path}

This study has led to a number of recommendations for evacuation strategies. The study found, as others have suggested, that a path perpendicular to the movement of the fallout cloud is usually better. However, the movement of the fallout cloud is not always something visible to the observer on the ground, especially in an urban area. For this reason, it is suggested that one take a path perpendicular to the imaginary line that connects his or her location and the presumed detonation location.

- Responders should take a path perpendicular to the line that connects their location with the detonation location, as mentioned in the paths section of Section 1, "Introduction."

- Responders should test to see which perpendicular path is better by sending scouts ahead-if they measure a significant decrease in radiation, the rest of the team should follow.

- Small increases (due to natural variation in the accumulation of fallout) in radiation rates are expected during evacuation. If the rate is

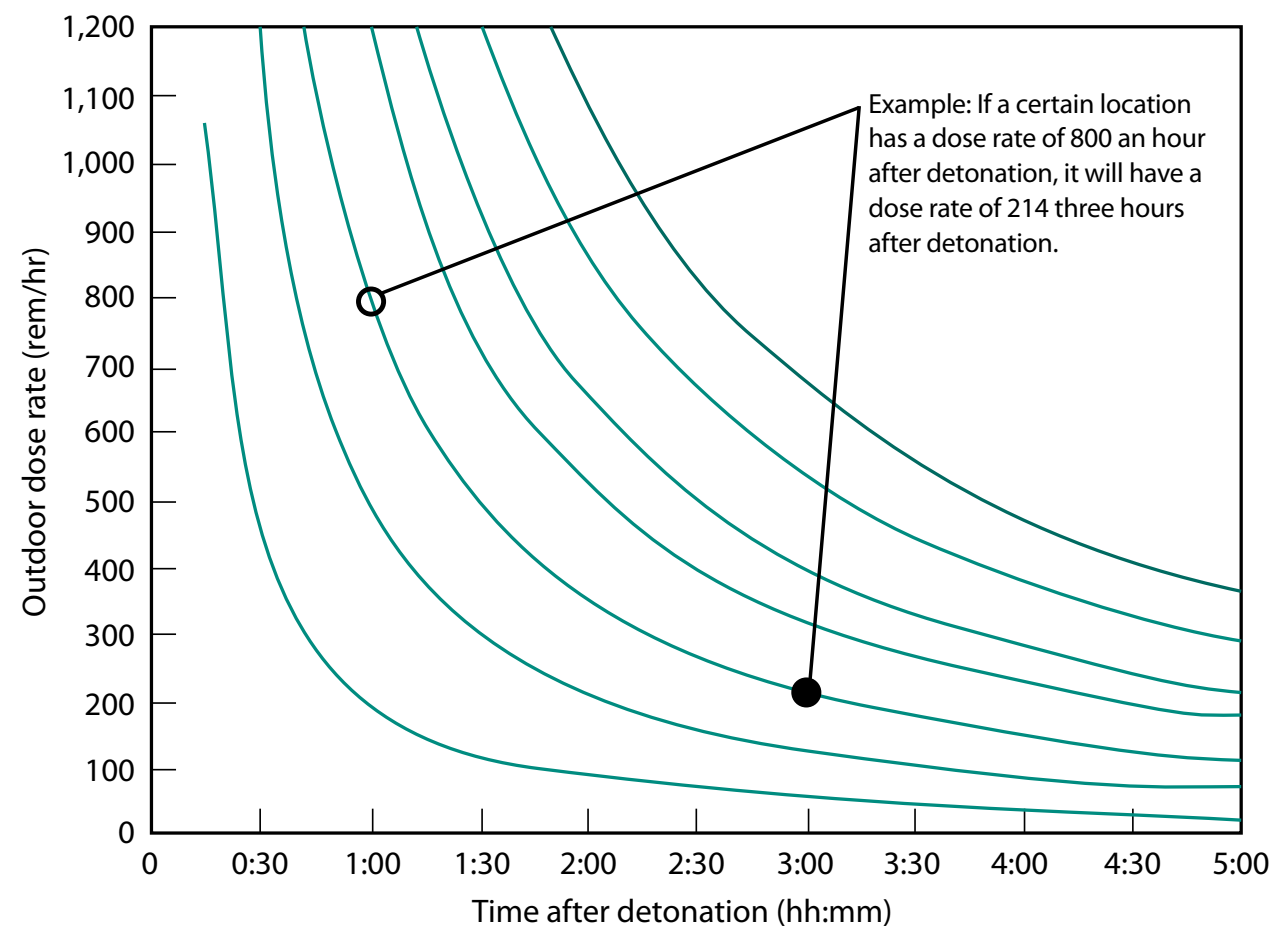

Figure 12. Fallout radiation decays rapidly as time passes. 
continuously increasing, however, responders should head a different direction or seek shelter in a nearby building that offers good protection.

- Fluctuations will exist in the dose rates during evacuation. Walking close to buildings will probably have a different exposure than walking in the middle of the street. Intersections will likely have higher dose rates. Try to walk through areas with lower dose rates.

- Moving through areas without fallout will reduce exposure. If possible, cut through buildings, underground parking garages, tunnels, or subways.

\subsubsection{Monitoring the Path}

Gamma dose-rate monitoring during evacuation will be difficult because the radiation rate is constantly decaying (decreasing with time). This means that meters may show that radiation is decreasing even when entering areas that have greater concentrations of fallout.

Figure 9, based on the power rule from the methodology section, shows how radiation decays overtime. To avoid entering areas of more dense fallout an evacuation route must grow farther from lines above it and closer to those below it.

Figure 12 shows three possible evacuations two hours after detonation. The blue path is the better lateral path out. The green path represents a lateral path that goes back through areas with more dense fallout. The yellow path represents a radial evacuation. Figure 13 shows what radiation rates first responders would read as they take each of the three paths presuming they begin their evacuation at 2 hours after the detonation. Note that the best path in this case actually takes the responder closer to the detonation location and into areas that may be more difficult to traverse. The black line represents the decaying (decreasing) dose rate just outside the shelter.
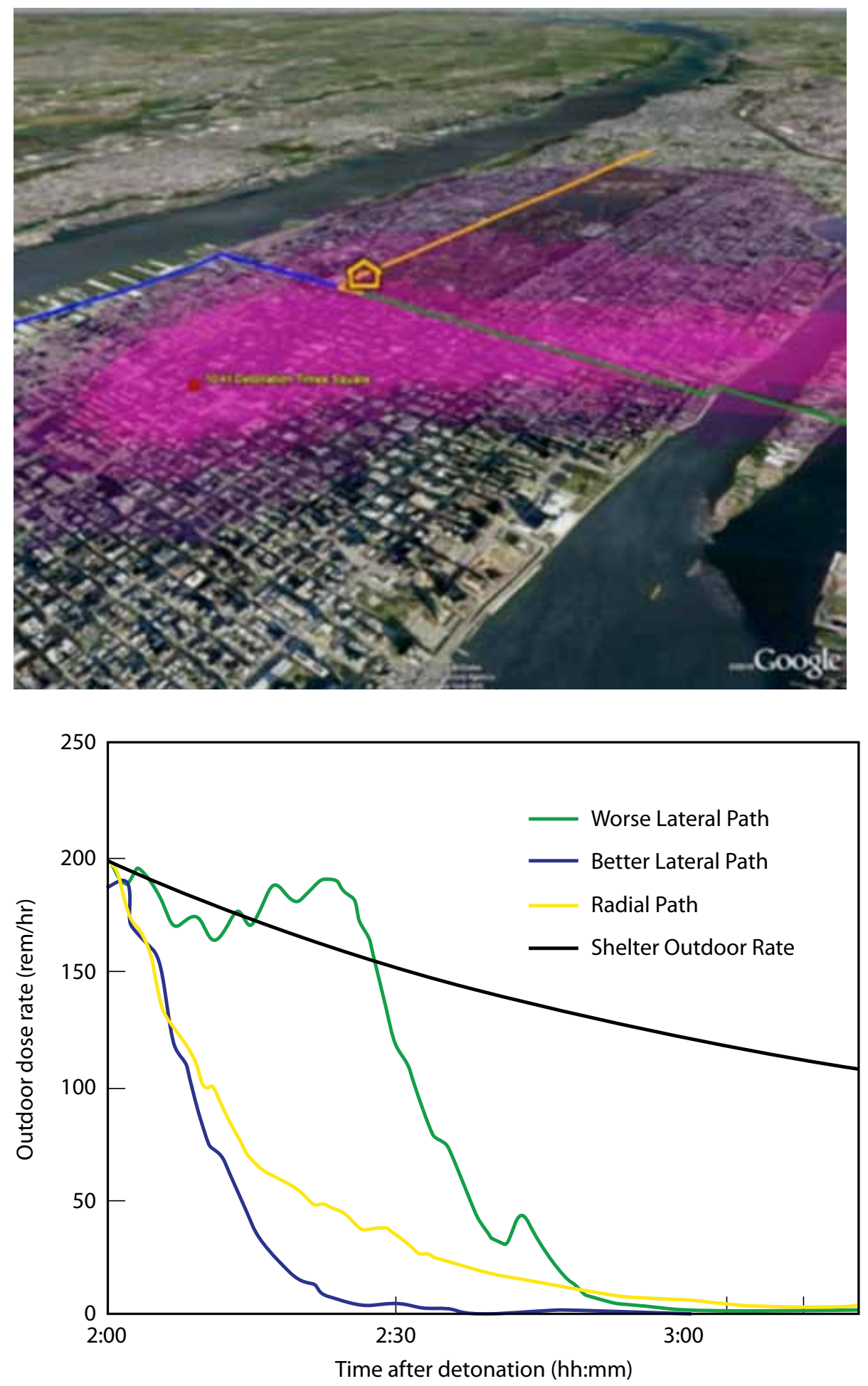

Figure 13. Radiation rates for first responders. 


\subsection{Examples}

\subsection{FDNY Ladder 115, Engine 258 Firehouse}

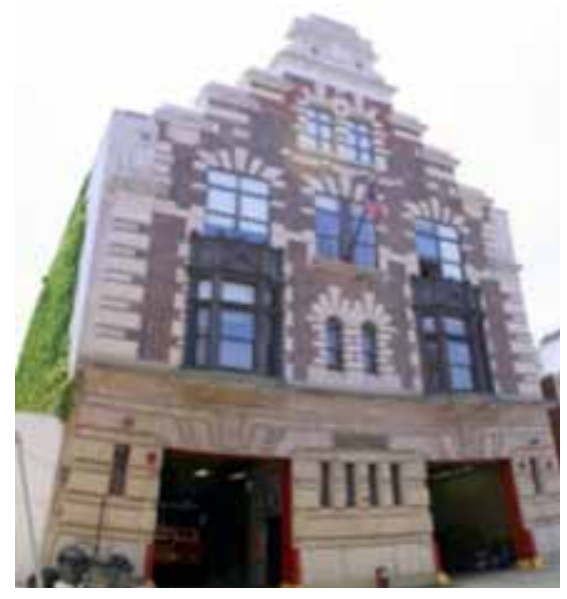

\section{Scenario}

Nuclear Detonation: 10-kt yield

- Location: Times Square at Ground Level.

- Time: Noon Jul 14, 2009.

- Firehouse: Four story Brick Structure: - Located on 47th Ave., Queens. -3.2 miles from detonation. -PF 50 (for sheltering in the basement).

\section{Timeline:}

12:00 PM Firefighters see the flash, soon hear the explosion of a nuclear bomb. Several of the windows may break, but this does not significantly affect the fallout protection offered by the building.

12:05 PM Through visual observations, crew suspects a nuclear explosion and moves down

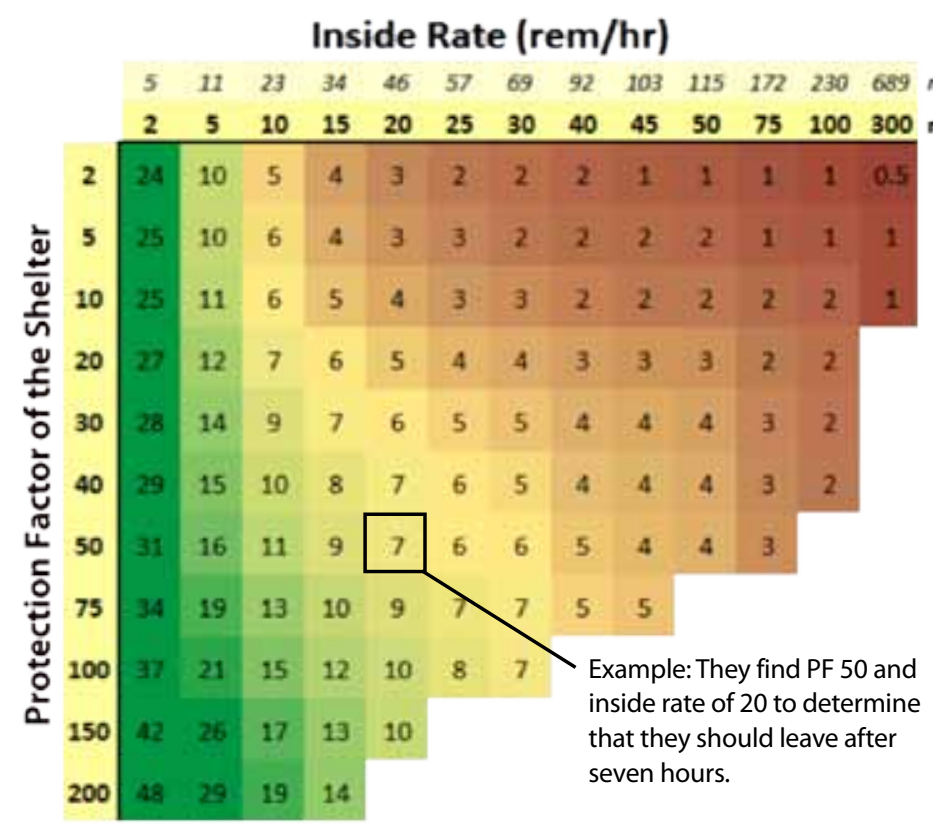

\begin{abstract}
measure $30 \mathrm{~min}$ after detonation measure $1 \mathrm{hr}$ after detonation
\end{abstract} \begin{tabular}{|l|}
\hline Time Guide \\
\hline Find better \\
\hline
\end{tabular} to the basement to protect themselves against fallout.

12:11 PM After a few minutes of almost no detectable radiation, the measured rate indoors climbs and peaks at about $140 \mathrm{rem} / \mathrm{hr}$, which indicates that fallout cloud has arrived to their station. Because they are in a basement with a PF of 50 , outside the radiation is 50 times as much, or $7000 \mathrm{rem} / \mathrm{hr}$.

12:30 PM Inside, the radiation rate is now about $40 \mathrm{rem} / \mathrm{hr}$. Outside, it is $2000 \mathrm{rem} / \mathrm{hr}$.

1:00 PM Inside, the radiation rate is now about $17 \mathrm{rem} / \mathrm{hr}$. Outside, it is about $860 \mathrm{rem} / \mathrm{hr}$. The firefighters look at the charts to see the recommended evacuation time (seven hours post-detonation). They also see a small benefit (a reduction of exposure of about 1 rem, giving a dose of 82 rem instead of 83 rem).

\section{Inside Rate (rem/hr)}

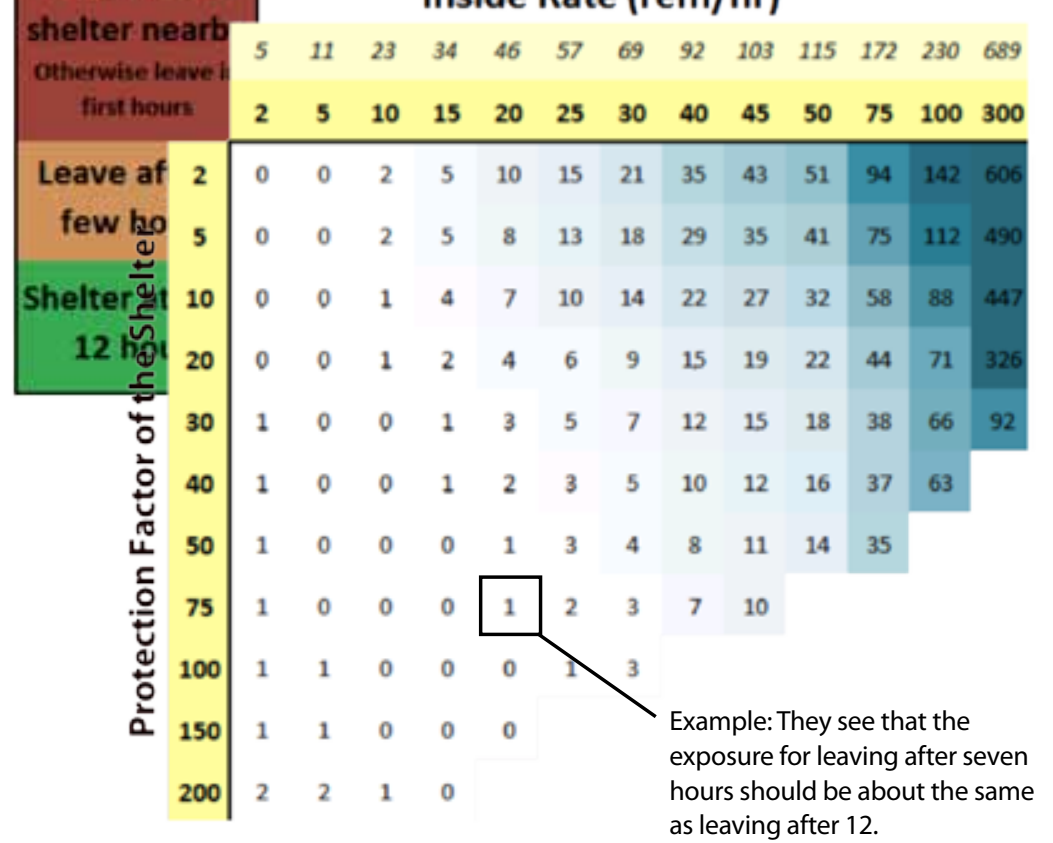



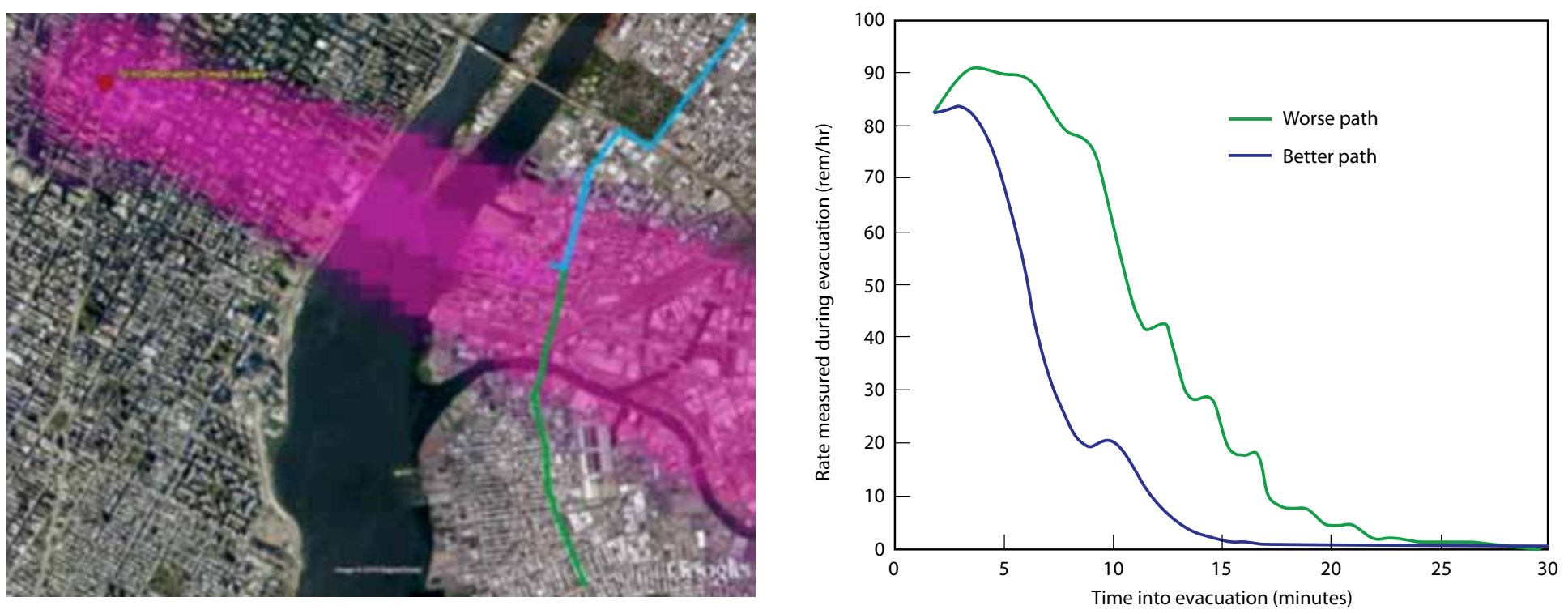

Figure 14. (left) Two likely paths for evacuation. (right) The radiation rate measured during evacuation.

7:00 PM The firefighters begin their evacuation. They will try to take the better lateral path. They must choose between the blue path and the green path. Both paths provide a reasonable way out. The blue path follows the better path and has a dose of $9 \mathrm{rem}$. The green path goes through an area with slightly more fallout and would have resulted in twice the evacuation dose (18 rem). Had they started out on the green path, they would have noticed the increasing radiation rates in the first three minutes. At this point, they could turn around and take the blue path and in the end receive a dose of 14 rem.

The optimal time to evacuate was $5 \frac{1}{1} 2$ hours after detonation, at which point the total (shelter + evacuation) dose would be 81 rem. An evacuation anytime between $31 / 2$ and 16 hours would cause a dose within 3 rem of the lowest possible dose. The firefighter's evacuation after seven hours gave them a total dose of 82 rem.

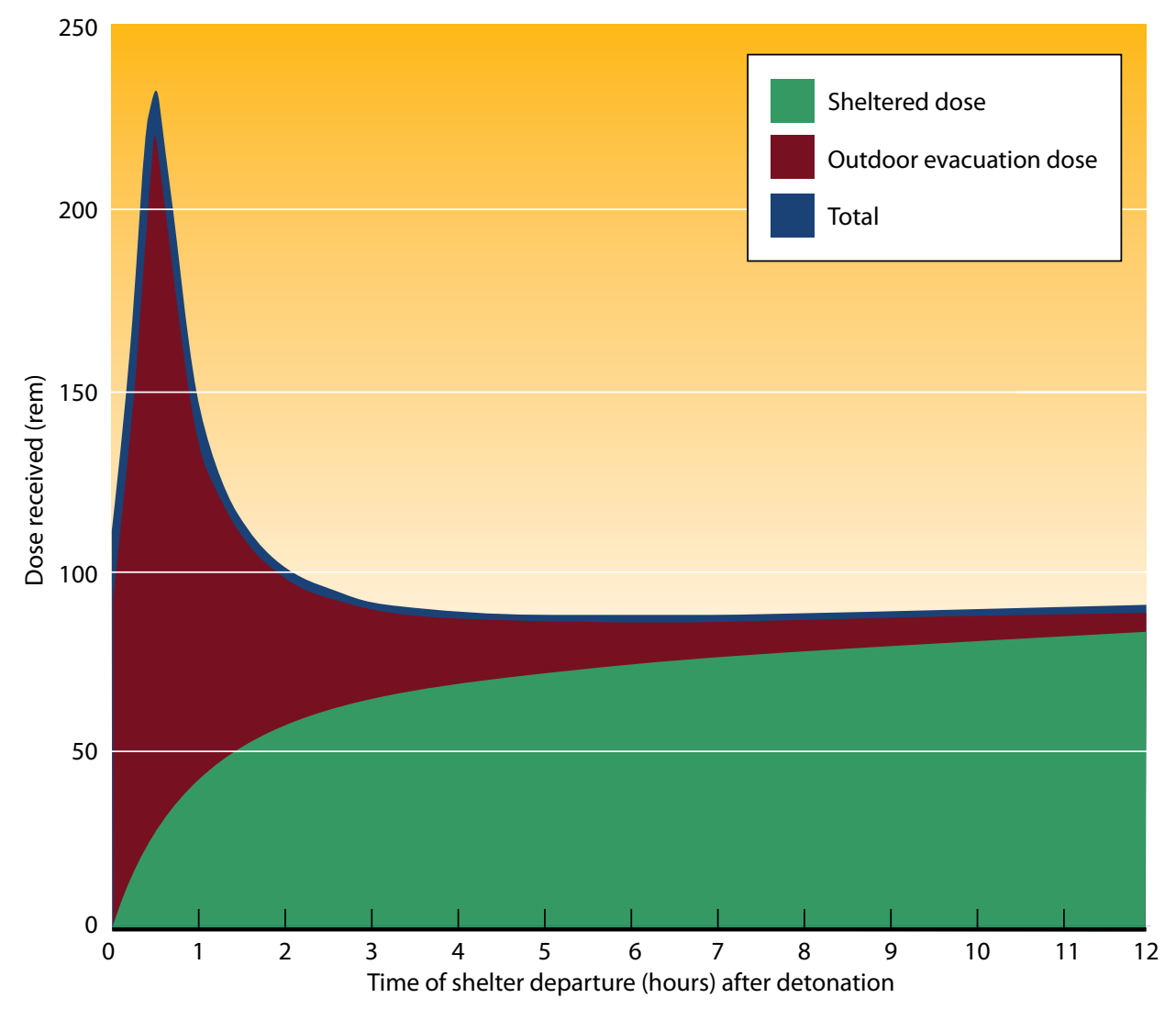

Figure 15. Evacuation anytime after 3.5 hours provides a reasonably low dose. 


\subsection{FDNY Battalion 8, Engine 2, Ladder 2 Firehouse}

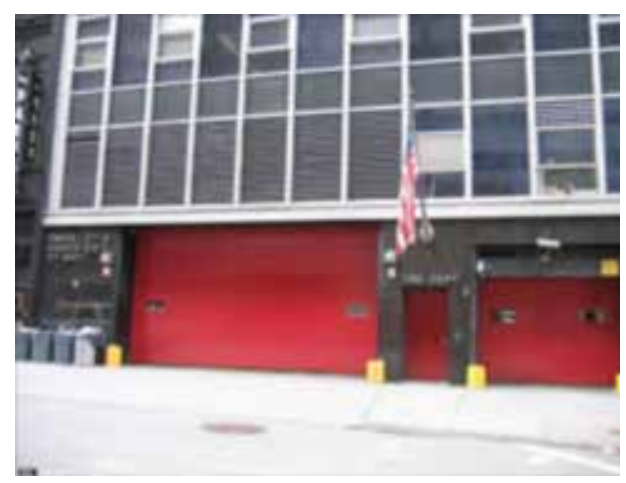

\section{Scenario}

Nuclear Detonation: 10-kt yield

- Altitude: Ground Level.

- Location:Times Square.

- Time: 8:00 PM Oct 14, 2009.

Firehouse

- Part of a large high-rise.

- 0.85 Miles from detonation.

- PF 100 (center of high-rise).

\section{Timeline}

8:00 PM

Light, sound, and blast felt.

Blast wave arrives a few seconds after flash. All windows and doors violently broken, but this does not significantly affect fallout protection offered by the building.

8:05 PM

Crew is unable to determine where the explosion occurred

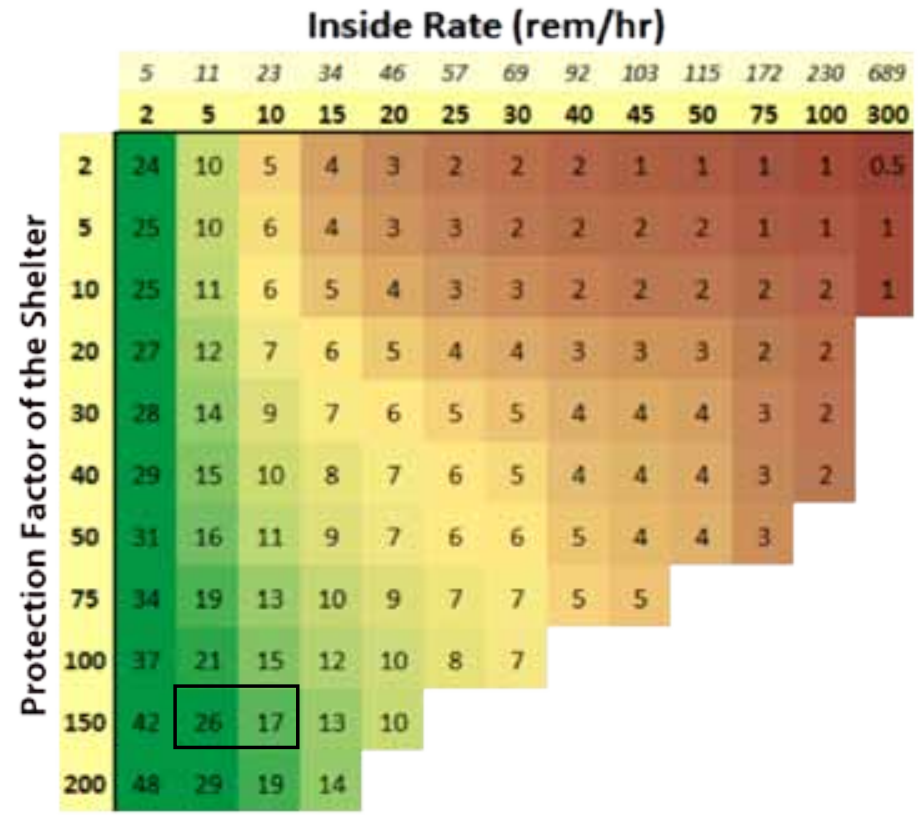

Chart recommends evacuation after

15 hours. Because there is no significant estimated benefit, an evacuation starting anytime after 12 hours is acceptable.

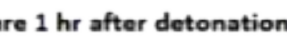

\begin{tabular}{|c|c|c|c|c|c|c|c|c|c|c|c|c|c|c|}
\hline \multicolumn{2}{|c|}{ Time Guide } & \multicolumn{13}{|c|}{ Inside Rate (rem/hr) } \\
\hline \multirow{2}{*}{\multicolumn{2}{|c|}{$\begin{array}{l}\text { Find better } \\
\text { shelter nearb }\end{array}$}} & $s$ & 11 & 23 & 34 & 46 & 57 & 69 & 92 & 103 & 115 & 172 & 230 & 689 \\
\hline & & 2 & 5 & 10 & 15 & 20 & 25 & 30 & 40 & 45 & 50 & 75 & 100 & 300 \\
\hline $\begin{array}{l}\text { otherwise te } \\
\text { first hou }\end{array}$ & 2 & 0 & 0 & 2 & 5 & 10 & 15 & 21 & 35 & 43 & 51 & 94 & 142 & 606 \\
\hline \multirow{2}{*}{ Leave ओं } & 5 & 0 & 0 & 2 & 5 & 8 & 13 & 18 & 29 & 35 & 41 & 75 & 112 & 490 \\
\hline & 10 & 0 & 0 & 1 & 4 & 7 & 10 & 14 & 22 & 27 & 32 & 58 & 88 & 447 \\
\hline \multirow{2}{*}{ 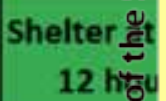 } & 20 & 0 & 0 & 1 & 2 & 4 & 6 & 9 & 15 & 19 & 22 & 44 & 71 & 326 \\
\hline & 30 & 1 & 0 & 0 & 1 & 3 & 5 & 7 & 12 & 15 & 18 & 38 & 66 & 92 \\
\hline \multirow{6}{*}{ 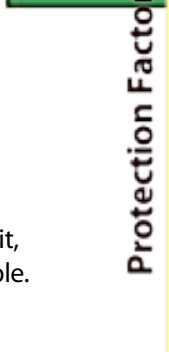 } & 40 & 1 & 0 & 0 & 1 & 2 & 3 & 5 & 10 & 12 & 16 & 37 & 63 & \\
\hline & 50 & 1 & 0 & 0 & 0 & 1 & 3 & 4 & 8 & 11 & 14 & 35 & & \\
\hline & 75 & 1 & 0 & 0 & 0 & 1 & 2 & 3 & 7 & 10 & & & & \\
\hline & 100 & 1 & 1 & 0 & 0 & 0 & 1 & 3 & & & & & & \\
\hline & 150 & 1 & 1 & 0 & 0 & 0 & & & & & & & & \\
\hline & 200 & 2 & 2 & 1 & 0 & & & & & & & & & \\
\hline
\end{tabular}

or cloud movement because of the visual obstructions in the urban environment, but moved to the center of the building as a precaution in case this was a nuclear event.

8:15 PM Fallout cloud arrives. Peak reading is about $20 \mathrm{rem} / \mathrm{hr}$ indoors or $2000 \mathrm{rem} / \mathrm{hr}$ outdoors.

8:30 PM Indoor rate is $16 \mathrm{rem} / \mathrm{hr}$. Outdoor rate is $1600 \mathrm{rem} / \mathrm{hr}$.

9:00 PM Indoor rate is $7 \mathrm{rem} / \mathrm{hr}$. Outdoor rate is $700 \mathrm{rem} / \mathrm{hr}$.

8:00 AM Begin evacuation.

8:30 AM Evacuation complete.

\section{Finding the better path}

The better lateral path is indicated by rapidly falling radiation rates in the first minutes of evacuation. The worse path shows a steady radiation rate for the first minutes of the path. 


\section{Shelter departure timing}

The best time to evacuate was 18 hours after detonation, when the total dose would be 29 rem. However, an evacuation anytime after four hours produces a dose of less than 40 rem and may be warranted if there are other hazards, such as fire, threatening the station.
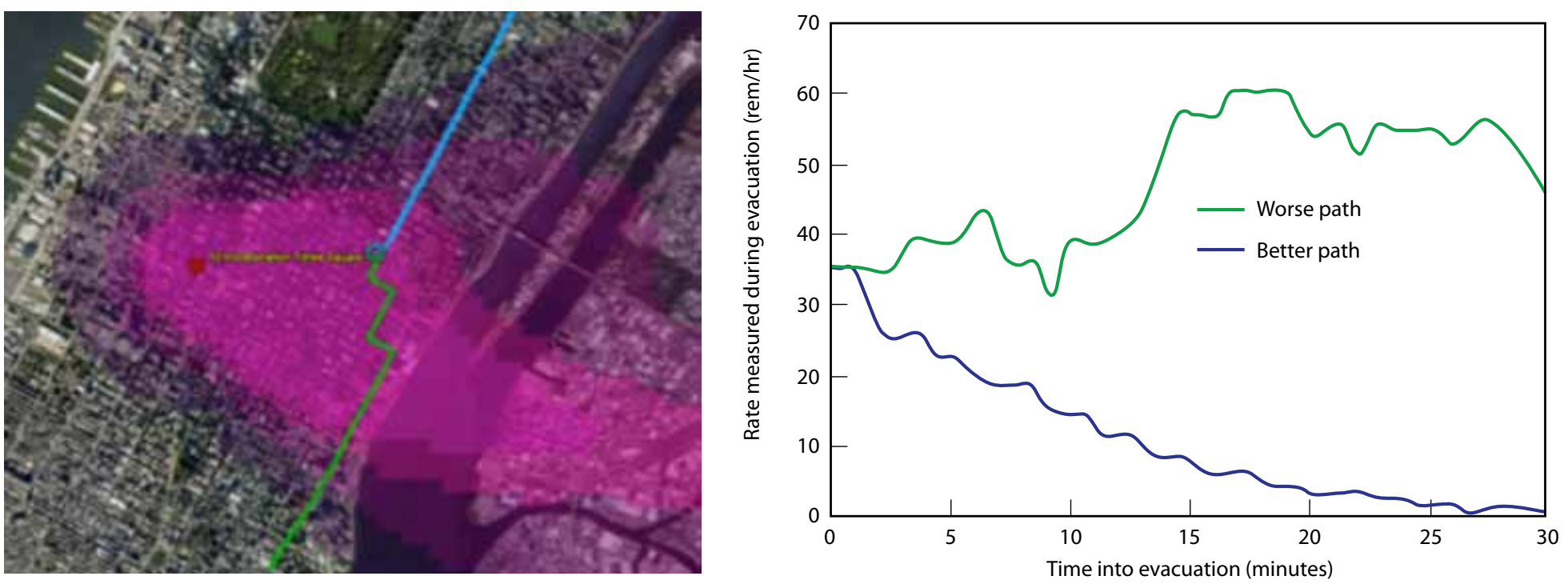

Figure 16. (left) Two likely paths for evacuation. (right) The radiation rate measured during evacuation.

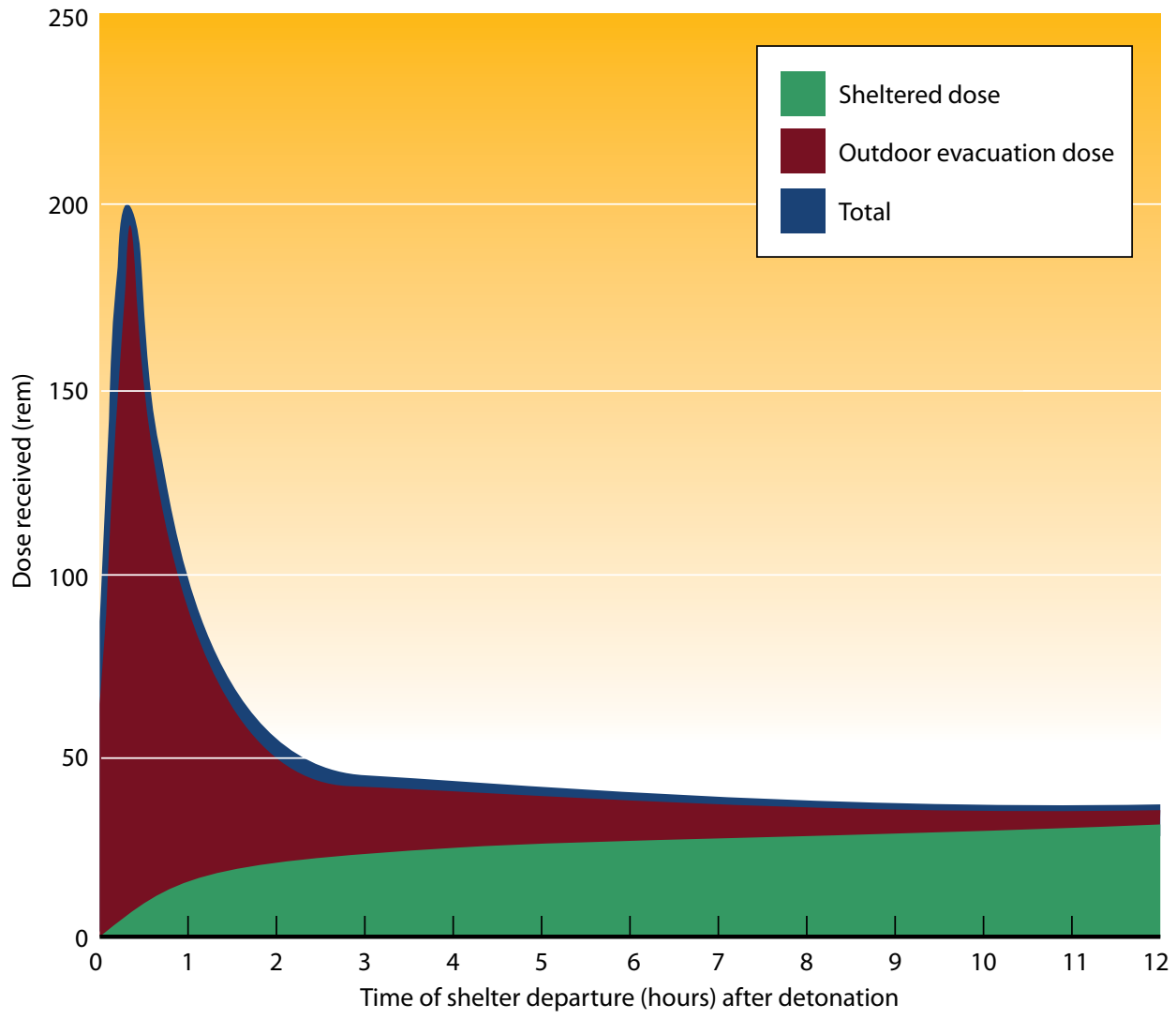

Figure 17. The best time to evacuation is 18 hours after detonation. 


\subsection{FDNY Engine 34, Ladder 21} Firehouse

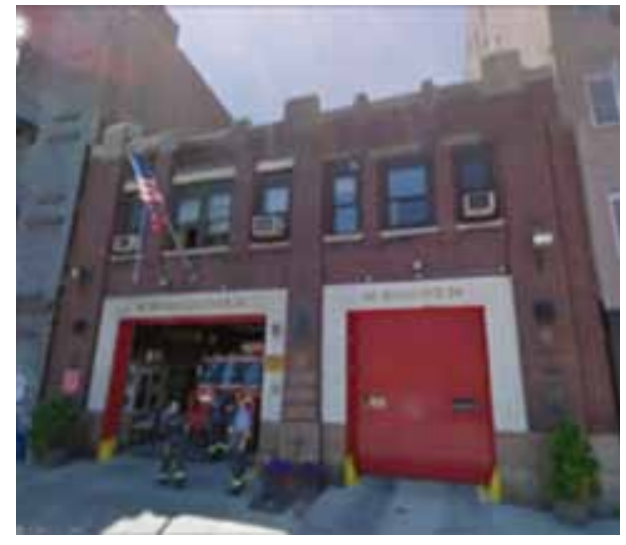

Scenario

Nuclear Detonation: 10-kt yield

- Altitude: Ground Level.

- Location:Times Square.

- Time: 12:00 PM Jun 14, 2009.

Firehouse

- Two-story brick structure.

- 0.5 miles from detonation.

- PF 20 (presumes no basement).

\section{Timeline}

12:00 PM Light, sound, and blast felt.

Blast wave arrives a few

seconds after flash. All

windows and doors are violently broken, but this does not significantly affect the fallout protection offered by the building. Building is partially shielded from blast effects by other buildings, but

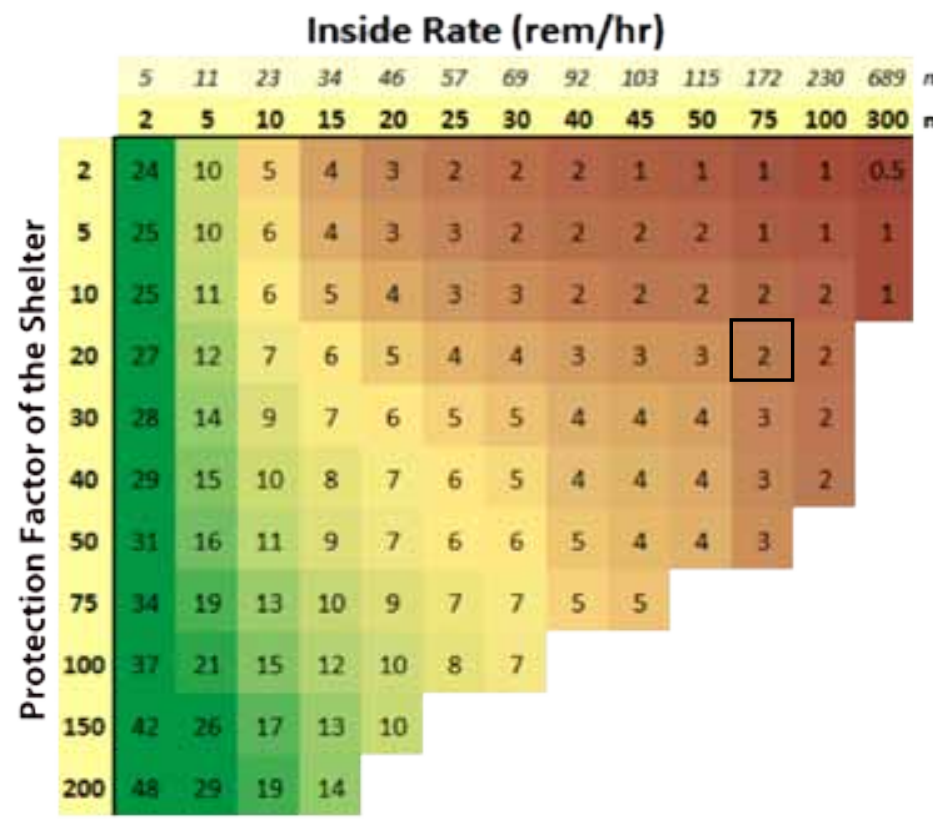

Chart recommends evacuation after two hours. There is an estimated 44-rem benefit to recommended evacuation time. measure 30 min after detonation measure $1 \mathrm{hr}$ after detonation
12:05 PM Crew is unable to determine where the explosion occurred or cloud movement because of the visual obstructions in the urban environment, but moved to the center of the building as a precaution in case this was a nuclear event.

12:06 PM Fallout cloud arrives. Peak reading is about $20 \mathrm{rem} / \mathrm{hr}$ indoors or $2000 \mathrm{rem} / \mathrm{hr}$ outdoors.

12:30 PM Indoor rate is $170 \mathrm{rem} / \mathrm{hr}$. Outdoor rate is $3400 \mathrm{rem} / \mathrm{hr}$.

1:00 PM Indoor rate is $75 \mathrm{rem} / \mathrm{hr}$. Outdoor rate is $1500 \mathrm{rem} / \mathrm{hr}$.

\section{Finding the better path}

The better lateral path is indicated by rapidly falling radiation rates in the first minutes of evacuation. Although

\section{Inside Rate (rem/hr)}

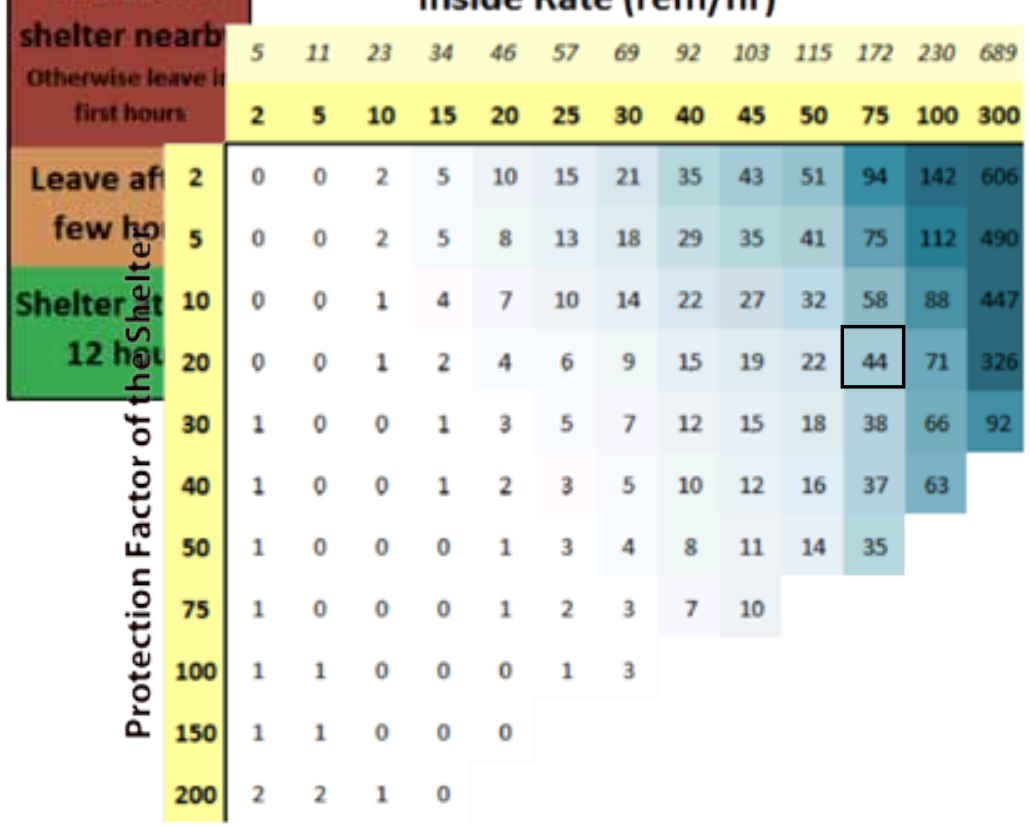


evacuation radiation levels would initially drop for both evacuation pathways (Figure 18 , right), the worse path passes through areas of increasing radiation and is longer to traverse (Figure 18, left).

\section{Shelter departure timing}

The best time to evacuate was $1 \frac{1}{2}$ hours after detonation, when the total dose would be $300 \mathrm{rem}$. The chart recommended an evacuation after two hours, when the dose would be 306 rem. An evacuation after 12 hours has a dose of 378 rem. By evacuating after two hours the dose was reduced by $68 \mathrm{rem}$. This is enough to reduce radiation illness severity.
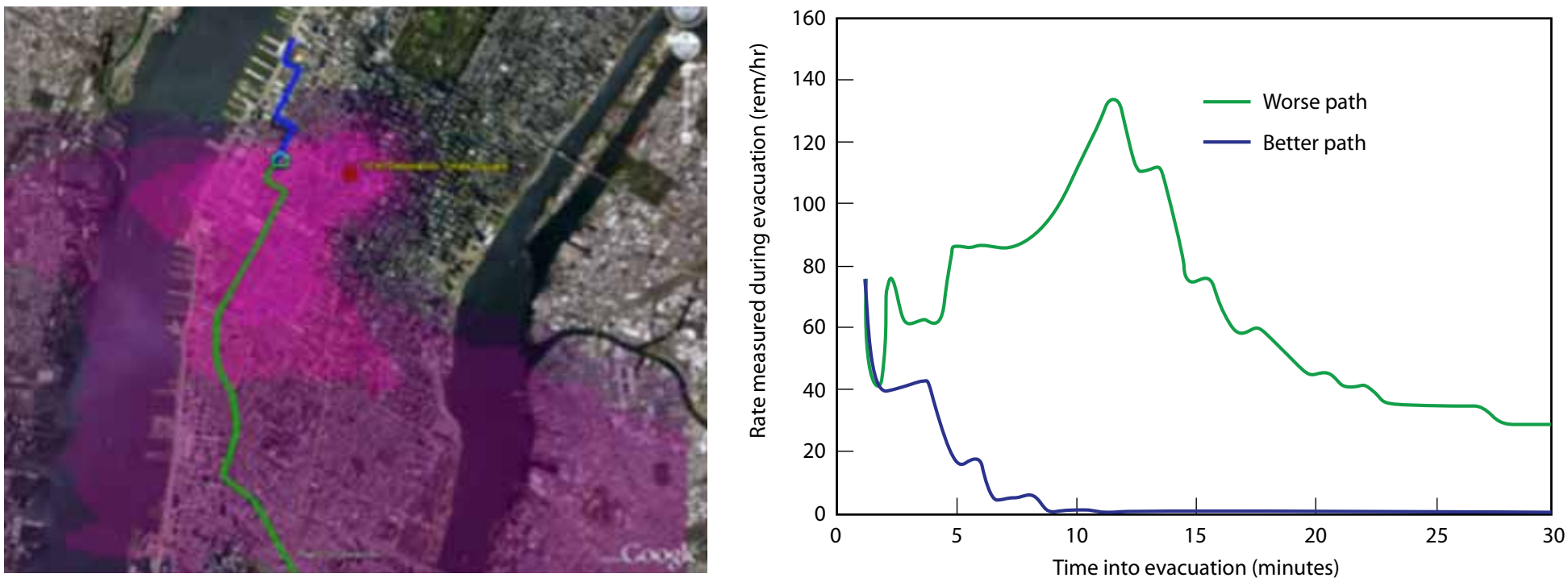

Figure 18. (left) Two likely paths for evacuation. (right) The radiation rate measured during evacuation.

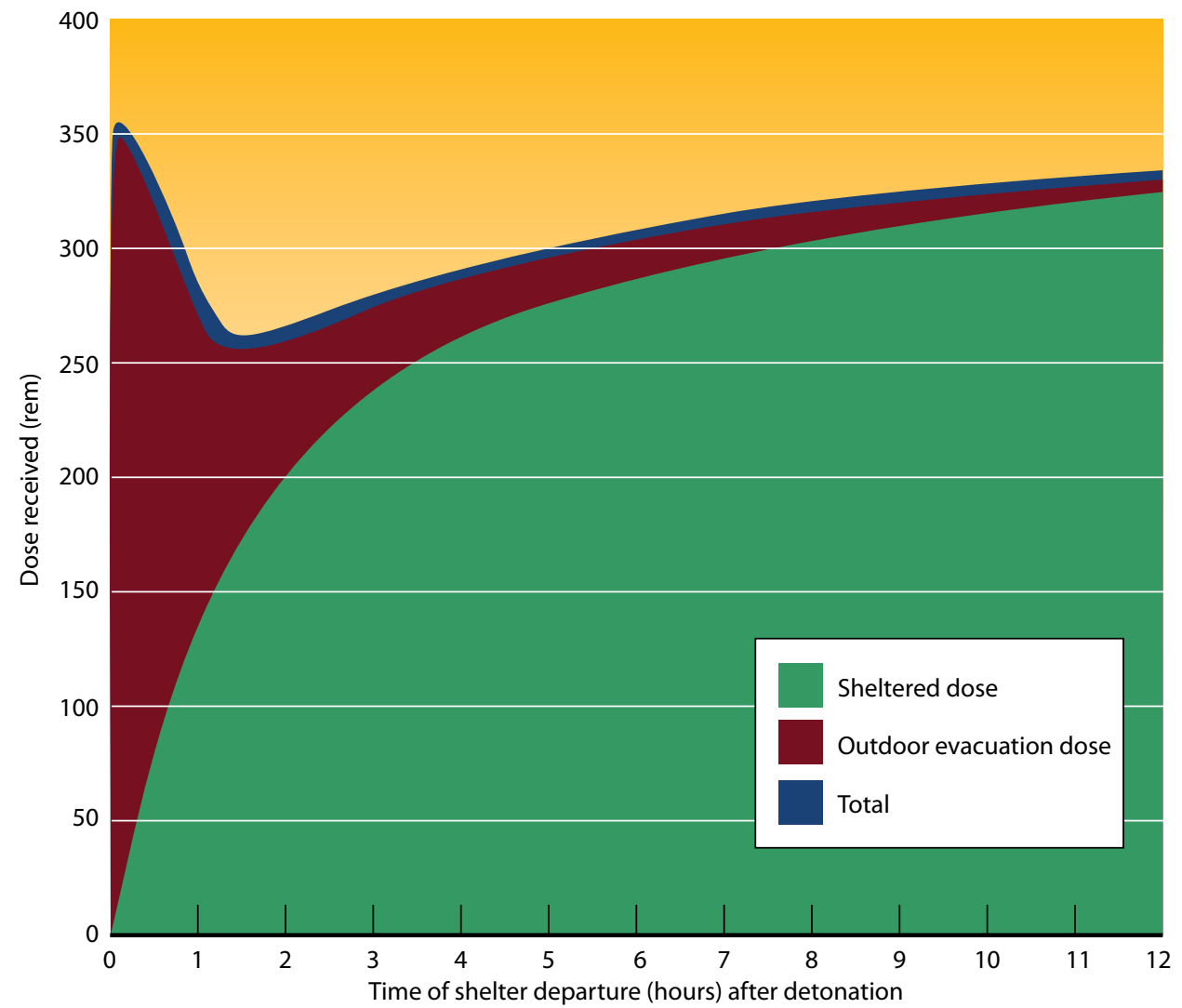

Figure 19. The best time to evacuate is 1.5 hours after detonation. 


\subsection{Next Steps}

\subsection{Statistical Study}

A statistical study of fallout patterns would be useful in determining how probable certain fallout patterns are for different locales. Because the correlation between evacuation dose and outdoor evacuation dose varies depending on fallout pattern, knowledge of what patterns are probable for a specific locale would be useful in determining location specific strategies.

\subsection{Broader Analysis and Risk Analysis}

A broader analysis of this subject should be performed prior to wide-scale implementation of the results. In particular, it would be useful to analyze shelter/evacuation strategies for many different detonation locations at different times of day and times of year. Analysis should be performed on a large random set of fallout patterns. This type of analysis would provide better insight into what probable evacuation doses are and how probable they are. Once the probability is found of taking a good versus a poor route, guidance should be developed to account for the risk of taking a poor route.

\subsection{Local Variation Study}

This study recommended that first responders find the best path by taking a lateral path with decreasing radiation rates. Local variation in an urban environment could make this task more difficult than it would appear. The NARAC data upon which this study was based did not take into account local variation. Analysis of local variation due to buildings, weather changes, and other factors would provide more insight into how to find the best possible evacuation route.

\subsection{First Responder Guides}

First responders with radiationmonitoring capability will need brief guides that can direct them regarding how to make sheltering and evacuation decisions. This type of guide should include relevant charts that give guidance as to when to evacuate. Guidance should also describe evacuation strategies. 


\subsection{References}

1. 1.Homeland Security Council Interagency Policy Coordination subcommittee for Preparedness and Response to Radiological and Nuclear Threats, Planning Guidance for Response to a Nuclear Detonation, Second Edition. Office of Science and Technology Policy, Executive Office of the President (www.ostp.gov) (June 2010).

2. Buddemeier, B. Dillion, M., Key Response Planning Factors for the Aftermath of Nuclear Terrorism, Lawrence Livermore National Laboratory, LLNL-TR-410067 (August 2009).

3. Glasstone, S. and Dolan, P.J., 1977, The Effects of Nuclear Weapons (third edition). Washington

D.C.: U.S. Government Printing Office, online at http://www.princeton.edu/ globsec/publications/ effects/effects.shtml, accessed December 2008. 


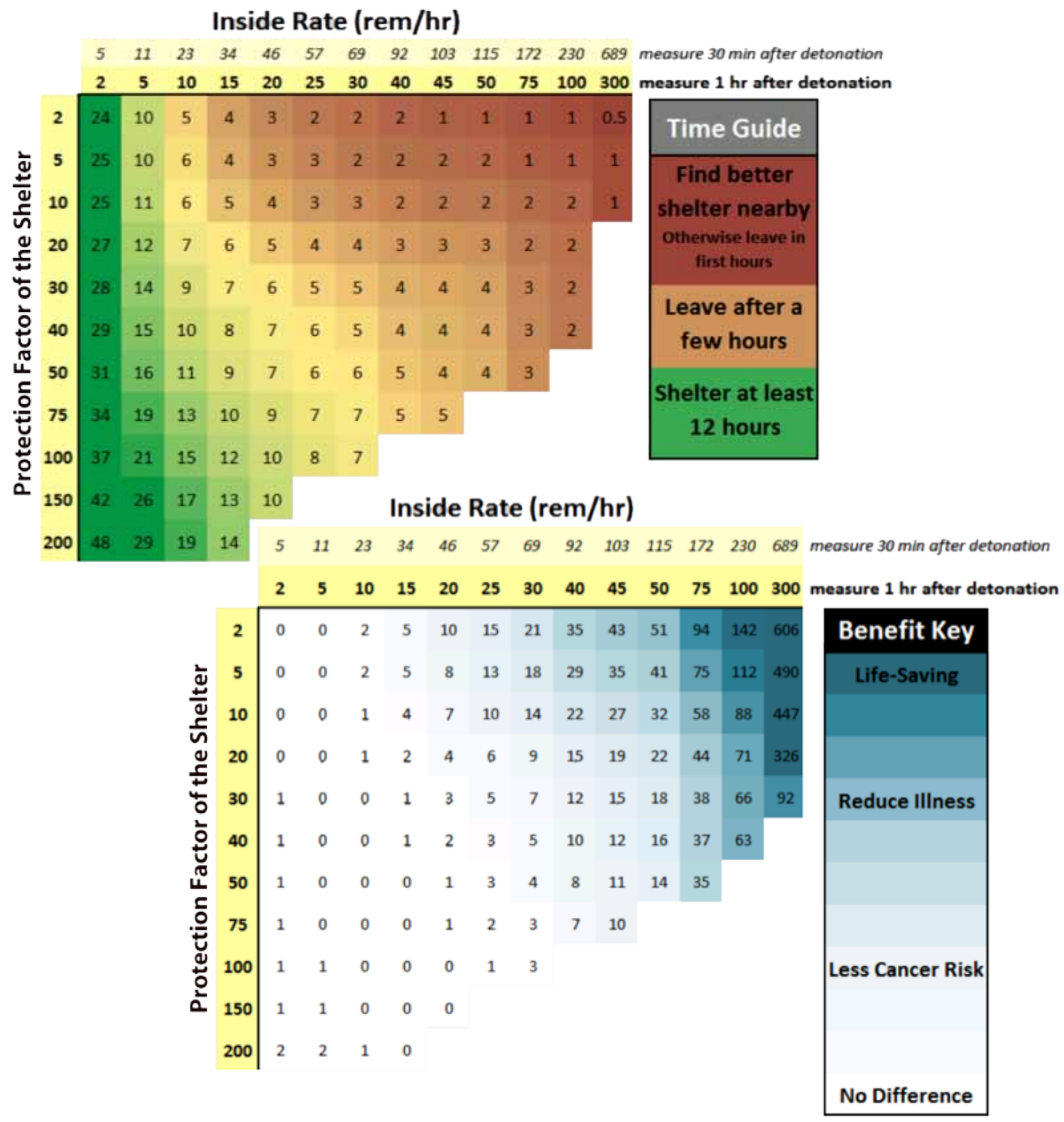

